\title{
Relationships between Deep Convection Updraft Characteristics and Satellite-Based Super Rapid Scan Mesoscale Atmospheric Motion Vector-Derived Flow
}

\author{
JASON M. APKE AND JOHN R. MECIKALSKI \\ Atmospheric Sciences Department, University of Alabama in Huntsville, Huntsville, Alabama \\ KRISTOPHER BEDKA \\ NASA Langley Research Center, Hampton, Virginia \\ EUGENE W. MCCAUL JR. \\ Universities Space Research Association, Huntsville, Alabama \\ CAMERON R. HOMEYER \\ School of Meteorology, University of Oklahoma, Norman, Oklahoma \\ CHRISTOPHER P. JEWETT \\ Earth Systems Science Center, University of Alabama in Huntsville, Huntsville, Alabama
}

(Manuscript received 30 March 2018, in final form 8 August 2018)

\begin{abstract}
Rapid acceleration of cloud-top outflow near vigorous storm updrafts can be readily observed in Geostationary Operational Environmental Satellite-14 (GOES-14) super rapid scan (SRS; 60 s) mode data. Conventional wisdom implies that this outflow is related to the intensity of updrafts and the formation of severe weather. However, from an SRS satellite perspective, the pairing of observed expansion and updraft intensity has not been objectively derived and documented. The goal of this study is to relate GOES-14 SRS-derived cloud-top horizontal divergence (CTD) over deep convection to internal updraft characteristics, and document evolution for severe and nonsevere thunderstorms. A new SRS flow derivation system is presented here to estimate storm-scale $(<20 \mathrm{~km})$ CTD. This CTD field is coupled with other proxies for storm updraft location and intensity such as overshooting tops (OTs), total lightning flash rates, and three-dimensional flow fields derived from dual-Doppler radar data. Objectively identified OTs with (without) matching CTD maxima were more (less) likely to be associated with radar-observed deep convection and severe weather reports at the ground, suggesting that some OTs were incorrectly identified. The correlation between CTD magnitude, maximum updraft speed, and total lightning was strongly positive for a nonsupercell pulse storm, and weakly positive for a supercell with multiple updraft pulses present. The relationship for the supercell was nonlinear, though larger flash rates are found during periods of larger CTD. Analysis here suggests that combining CTD with OTs and total lightning could have severe weather nowcasting value.
\end{abstract}

\section{Introduction}

Experimentation with fine temporal resolution $(\leq 1 \mathrm{~min})$ super rapid scan (SRS) operations for Geostationary (GEO) Operational Environmental Satellite (GOES) data over deep convection (DC) has revealed that outflow acceleration and turbulent motion in overshooting

\footnotetext{
Corresponding author: Jason Apke, jason.apke@gmail.com
}

cloud tops (OTs) associated with strong storms can now be observed (Schmit et al. 2013; Bedka et al. 2015; Line et al. 2016; Apke et al. 2016, hereafter A16; Bedka et al. 2018). It is natural to assume that this acceleration is associated with updraft intensification, though the correspondence with SRS GEO satellite inferences of these flows and what occurs internally with updrafts in DC has not been documented. There is clear operational and research value in the ability to objectively infer 
updraft characteristics in DC, as a strong updraft can facilitate large hail growth (Pruppacher and Klett 1997), lead to the formation of strong downburst winds (Fujita 1981), and promote processes involved with tornadogenesis at the ground (Orf et al. 2017). For example, Witt and Nelson (1991), Boustead (2008), and Blair et al. (2011) all used the maximum single-Doppler radar-derived radial divergence to infer the strength of observed updrafts and found positive correlations to ground-reported hail diameter. Schultz et al. (2009, 2011) found that "jumps" in observed cloud-to-cloud and cloud-to-ground (total) lightning flash rates (FRs) are related to strong updraft acceleration that precede severe weather (strong winds $>25 \mathrm{~m} \mathrm{~s}^{-1}$, large hail $>2.54 \mathrm{~cm}$ in diameter, and tornadoes) by as much as $\sim 20 \mathrm{~min}$. It is possible that updraft characteristics in DC can be similarly inferred via automated retrieval of storm outflow rate depicted by SRS GEO imagery.

A16 found that SRS data could be used to objectively derive realistic gridded storm complex-scale $(>20 \mathrm{~km}$ storm-top diameter) anvil-level flow fields over DC using cloud feature tracking from visible (VIS) imagery, also known as mesoscale atmospheric motion vectors (mAMVs; Bedka and Mecikalski 2005). Unfortunately, no validation yet exists on SRS mAMV datasets given the recent availability of imagery with sufficient navigation and registration quality. It is therefore unclear if objectively derived flows from mAMVs over DC, such as cloud-top horizontal divergence (CTD), represent motion consistent with understanding of dynamics in the atmosphere, or if they represent noise present in the imagery itself. For example, derived CTD over DC through mass continuity, if physically meaningful, would be maximized where updrafts are the strongest (specifically, where the change in vertical mass flux with height is minimized) and collocated with other indicators of strong updrafts at the cloud top. As will be discussed in this article, however, there are several limitations to deriving mAMVs with 1-min imagery, which may change derived CTD. The sample size from A16 was too small (six storms) to determine if CTD represented a consistent and physically meaningful signal, and the derived flow fields in the sample often exhibited artifacts in laminar cloud fields where mAMV spatial density was low.

This paper seeks to expand upon previous studies by relating an updated GOES-SRS CTD derivation system to other storm intensity proxies derived from satellite, ground-based radar, and very high frequency (VHF) lightning mapping array (LMA) data. The goals are 1) to understand if SRS-based CTD products provide meaningful and temporally consistent characterizations of updrafts in DC and 2) to determine the relevance of updraft accelerations inferred in these multisensor products for severe weather nowcasting. Extending the findings of A16, we hypothesize that storm-scale CTD $(<20 \mathrm{~km}$; finer than A16) should peak in space and time near OT regions depicted by GOES, and the CTD maximum will further be correlated to internal and near-cloud-top updraft characteristics such as updraft volume and magnitude. The findings here will both direct development of future products and further our understanding of observed outflow over DC in nextgeneration GEO satellite imagery data.

\section{Background}

\section{a. Mesoscale atmospheric motion vectors}

AMVs have been derived from GOES imagery operationally for over 20 years (Velden et al. 1997, 1998). The AMVs are derived by tracking targets (such as gradients, minima, and maxima) in a sequence of three GOES images (Nieman et al. 1997), typically separated by $\sim 15 \mathrm{~min}$. The heights of identified targets are first estimated by comparing infrared (IR) and water vapor (WV) channel brightness temperature $\left(T_{B}\right)$ to numerical weather prediction (NWP) data (Nieman et al. 1993). The same NWP information is used to forecast future target displacement to the next GOES image. Tracking in the AMV approach is typically sum-of-square error minimization between the brightness counts of the target and a search region of equivalent size in the next image within a permissible area around the forecast displacement vector. With three images, this operation is repeated backward in time and the two displacements are averaged to one motion. The final AMVs are quality controlled with comparison to nearby AMVs and NWP information to extract synoptic-scale flow (Hayden and Purser 1995; Holmlund 1998).

Bedka and Mecikalski (2005) used the AMV algorithm with weakened quality control constraints to generate nongradient wind-balanced flows in the output, the socalled mAMVs. When compared to rawinsonde and vertical wind profiler observations, these mAMVs provided weaker agreement than AMVs used for NWP assimilation. However, they were found to better depict mesoscale flows not captured by rawinsondes, such as those along outflow boundaries, and in zones strongly influenced by vertical wind shear, convective outflow, and mid- to upper-level divergence and vorticity patterns (Bedka et al. 2009). Velden et al. (2005) noted that image feature tracking approaches can be improved with finer temporal resolution data, and that spatially dense AMVs (like mAMVs) can capture divergence associated with DC, which may be related back to storm updraft intensity. 
There are a few limitations to mAMV derivation that the reader should be aware of. Pattern matching schemes assume that cloud motion represents actual motion, which may not be the case with gravity waves or with scenes containing rapid condensation or evaporation of cloud droplets (Bresky et al. 2012). "Bubbling" common in DC may also look like horizontal motion with sum-of-square error minimization tracking if it occurs below the scanning time scale of GOES images (which is less of a problem for SRS imagery than 5- to 15-min data). Navigation and registration errors, however, cause larger mAMV displacements when using 1-min imagery (e.g., a $\sim 1$ VIS pixel navigation error in GOES-14 can result in an $\sim 8 \mathrm{~m} \mathrm{~s}^{-1}$ mAMV shift), thus images must be accurately mapped from frame to frame (Hasler et al. 1998; Velden et al. 2005). No validation yet exists with 1-min mAMVs; however, new mesoscale versions of the GOES-16 derived motion winds (Bresky et al. 2012) will be validated over scenes with DC when operational.

In A16, the mAMV approach was applied to experimental GOES-14 SRS data to derive storm-scale flow fields that depicted rotational motion atop a supercell storm in central Colorado. A16 noted that CTD was much larger for severe supercell storms than for nonsupercells. The geometry of CTD and rotation matched idealized NWP simulations of supercells; however, both fields were sensitive to the spatial density of mAMVs over DC and would frequently exhibit fluctuations that were not consistent with changes in radar reflectivity echo tops or storm severity. These fluctuations indicated room for improvement with the flow fields derived. Because of these artifacts, no attempt has yet been made to quantitatively compare SRS-derived CTD to updraft location, size, and intensity. This study, therefore, takes advantage of the observable signatures in satellite, radar data, and LMAs to examine how well the CTD fields from an improved A16 mAMV approach (described in section 3c) characterize kinematics in DC.

\section{b. Remote sensing observations of convective updrafts}

Ground-based multi-Doppler radar networks have traditionally been used to characterize the three-dimensional updraft flow structure of severe DC for many years, typically over small domains (e.g., Ray 1976; Ray et al. 1978; Lemon and Doswell 1979; Ray et al. 1980; Knupp 1996; Frame et al. 2009). With just a single-Doppler radar, strong updrafts are inferred in zones of strong horizontal radar reflectivity $Z_{H}$ with locally high echo tops (e.g., Starzec et al. 2017) or bounded weak echo regions (BWER; Lemon et al. 1978). These signatures work well when radar information is available, though large gaps in radar coverage remain over oceanic regions and countries without radar networks. Radar observations of updrafts in DC have been complemented by total lightning measurements. Total lightning flashes observed from LMAs (Rison et al. 1999; Krehbiel et al. 2000) have been correlated to mixed-phase updraft strength and volume (Deierling and Petersen 2008; Schultz et al. 2015, 2017). The spatial distribution of LMA sources sometimes reveals lightning "holes" or "rings" in intense storms (i.e., horizontal regions with few lightning sources within the strongest updraft cores, surrounded by rings of greater flash density; Krehbiel et al. 2000).

Without ground-based information, updraft tracking is performed with GEO satellites that collect data over significantly larger domains. With mature DC, updrafts are tracked by identification of domelike protrusions above the cumulonimbus anvil (OTs; Setvák et al. 2010; Bedka et al. 2012; BK16). OTs are ubiquitous within DC (Bedka et al. 2010). Other satellite signatures used related to strong updrafts, such as the "enhanced-V" (McCann 1983; Brunner et al. 2007) and the "cold ring" (Setvák et al. 2010), are typically generated by aboveanvil cirrus plumes (Wang 2003, 2007; Bedka et al. 2015; Homeyer et al. 2017; Bedka et al. 2018).

The relationship between satellite-based OT detections and updrafts comes with a few caveats. For example, OTs that are long lived and penetrate deep enough into the stratosphere can appear warmer (rather than colder) than the surrounding anvil, making objective OT identification challenging with IR information alone. Furthermore, IR temperature data may have too coarse a spatial resolution (nominally $+5 \mathrm{~km}$ over the United States from GOES-14) to adequately resolve small and/or weak OTs. Griffin et al. (2016) also show that $\sim 4-\mathrm{K} T_{B}$ changes can equate to a $1-\mathrm{km}$ change in cloud-top height within prior-generation $4 \mathrm{~km}$ (at nadir) GOES-8-15 data. These subtle $T_{B}$ changes may be easy to misinterpret by operational forecasters especially when fixed color enhancements are used for satellite image display, where one color may depict a range of several kelvin. These drawbacks in subjective and objective OT identification suggest a need to combine OT observations with other datasets for optimal updraft location and intensity recognition. OT detection has not yet taken advantage of the temporal evolution and persistence of updrafts depicted by SRS GOES-14 and -16 imagery. Thus, OT detection can be susceptible to false alarms within complex $T_{B}$ patterns in cold outflow over DC that may appear OT-like within individual IR image snapshots. Recent advances in OT identification include use of shape and texture information from VIS channels to mitigate the challenges associated with IR data (Bedka and Khlopenkov 2016, hereafter BK16). 
The temporal evolution of the SRS images and flow derived from mAMVs, if determined physically meaningful, may be useful to increase confidence in OT identification, and help to classify which OTs are likely to produce severe weather.

\section{Data and methods}

\section{a. Data}

To determine if CTD is physically meaningful, radar, satellite, and LMA data were collected during the SRS experiments in 2014 and 2015. Three GOES-14 channels were used for mAMV derivation and OT observations: the VIS band $(0.63 \mu \mathrm{m})$, the WV band $(6.48 \mu \mathrm{m})$, and the surface or cloud-top temperature "window" IR band $(10.7 \mu \mathrm{m})$. GOES-14 SRS data offered a $\sim 1 \mathrm{~km}$ per pixel VIS and $\sim 4 \mathrm{~km}$ per pixel WV and IR spatial resolution at nadir every minute.

Radar datasets used here include the Level-II Weather Surveillance Radar-1988 Doppler (WSR-88D; Crum and Alberty 1993) acquired from the National Climatic Data Center Archive Information Request System (NCDC AIRS, https://www.ncdc.noaa.gov) and the northern Alabama Advanced Radar for Meteorological and Operational Research (ARMOR; Schultz et al. 2012; Knupp et al. 2014) located at the Huntsville, Alabama, airport. Two WSR-88D systems were used: the Front Range, Colorado, system (KFTG), and the Hytop, Alabama, system (KHTX). ARMOR data were combined with KHTX to perform dualDoppler three-dimensional flow derivation. For large domains considered in the OT and CTD comparison described in section 3d, we generated a 5-min version of the Gridded WSR-88D dataset (GridRad; Cooney et al. 2018), which merges data from the 125 CONUS WSR-88D systems into a $0.02^{\circ} \times 0.02^{\circ} \times 1 \mathrm{~km}$ longitude-latitude-altitude grid with a distance- and time-weighted composite scheme (Homeyer and Bowman 2017).

For total lightning information, the Colorado LMA (COLMA; Krehbiel et al. 2012; Lang et al. 2014), west Texas LMA (WTLMA; Bruning et al. 2011), and northern Alabama LMA (NALMA; Koshak et al. 2004) data were collected. Sources from LMAs within permissible spatiotemporal range of each other were grouped into lightning flashes using methods described by McCaul et al. (2005). The sum of the flashes for each isolated cell was computed over a $0.2^{\circ} \times 0.2^{\circ}\left(0.3^{\circ} \times 0.3^{\circ}\right)$ latitude by longitude analysis box centered on the cell of interest for 18 August 2014 (21 May 2014, 27 May 2015, and 4 June 2015; described below), and the evolving trends in FR were compared to CTD and inferred updraft characteristics. When multiple strong updrafts were present (as for 21 May 2014), we supplemented the FR data with grids of flash extent density
(FED) data. FED counts individual flashes within a $0.01^{\circ} \times$ $0.01^{\circ}$ longitude-latitude grid box regardless of whether the LMA source is a flash origin point. The raw stormwide total lightning FRs and FR trends are also analyzed using a 10-min box-car average to create a smoothed FR for comparison with derived updraft strength, $T_{B}$, and CTD.

\section{b. Case studies}

Five case studies were analyzed with dates, times, and domains shown in Table 1. Four of these case studies, 21 May 2014, 19 May 2015, 27 May 2015, and 4 June 2015, were events with widespread DC containing a variety of severe weather reports from the National Centers for Environmental Information (NCEI) storm events database (NCEI 2018) used in the OT and CTD comparison in section 3d. The fifth case study, 18 August 2014, was localized DC within the ARMOR and KHTX dual-Doppler and NALMA domain in northern Alabama. Discrete supercells (among other convection) were also sampled with LMAs on 21 May 2014 (the Adams County supercell; a tornadic supercell in central Colorado), 27 May 2015 (the Hale County supercell; a hailstorm in central Texas), and 4 June 2015 (the Elbert County supercell; a tornadic supercell in southern Colorado). The Adams County supercell is closely examined here. This storm was chosen because it was discrete; namely, there was limited cirrus outflow from other nearby storms to influence the mAMV field analysis and no other nearby lightning activity to bias our automated total lightning FR and statistics.

\section{c. Derivation of $m A M V$ cloud-top divergence (CTD)}

The mAMV approach used here is identical to Bedka and Mecikalski (2005) and A16, with the following exceptions: the targets are smaller $(5 \times 5$ pixel image boxes), and the VIS brightness count gradient threshold (which permits the selection of a candidate in the image as a target) is lower (set to 4 brightness counts) to yield more mAMVs in laminar cloud scenery. For CTD derivation, the point source mAMVs over a 5-min period (six individual mAMV sets including 0-min corrected for storm motion; see A16 section 3b) were gridded into a flow field of $u$ - and $v$-component wind using a recursive filter (RF; Fig. 1) analysis system (Purser and McQuigg 1982; Hayden and Purser 1995), described in the appendix. Large objective analysis CTD artifacts derived in A16 (which form because the original Barnes analysis incorrectly interpolated $u$ - and $v$-component information where few mAMVs exist) are reduced with the RF approach (e.g., see purple circle in Figs. 1c and 1d). It should be noted that derived CTD values were still smoothed as in A16 and represent only a fraction of the actual CTD present as a result of objective analysis limitations. The product developed here has 
TABLE 1. Datasets and domains used for OT to CTD product comparison.

\begin{tabular}{lcl}
\hline \hline Case study & Time duration & \multicolumn{1}{c}{$\begin{array}{c}\text { Domain (west lon, east } \\
\text { lon, south lat, north lat) }\end{array}$} \\
\hline 21 May 2014 & $1900-0000$ UTC & $106^{\circ} \mathrm{W}, 101^{\circ} \mathrm{W}, 37.5^{\circ} \mathrm{N}, 41^{\circ} \mathrm{N}$ \\
18 Aug 2014 & $2000-2300$ UTC & $88.5^{\circ} \mathrm{W}, 84.5^{\circ} \mathrm{W}, 33.5^{\circ} \mathrm{N}, 36.5^{\circ} \mathrm{N}$ \\
19 May 2015 & $1800-0000$ UTC & $103^{\circ} \mathrm{W}, 94^{\circ} \mathrm{W}, 29^{\circ} \mathrm{N}, 37^{\circ} \mathrm{N}$ \\
27 May 2015 & $1800-0200$ UTC & $104^{\circ} \mathrm{W}, 96^{\circ} \mathrm{W}, 30^{\circ} \mathrm{N}, 41.5^{\circ} \mathrm{N}$ \\
4 Jun 2015 & $1800-0300$ UTC & $108^{\circ} \mathrm{W}, 94^{\circ} \mathrm{W}, 34^{\circ} \mathrm{N}, 43^{\circ} \mathrm{N}$ \\
\hline
\end{tabular}

been named the super rapid scan anvil level flow system (SRSAL).

\section{d. OT and CTD comparison}

We seek to understand how often SRSAL CTD identified an updraft in DC, how close the CTD maximum is typically located to an updraft detected using the BK16 OT detection methods, and how the characteristics of the OTs found near CTD maxima compared to OTs outside notable CTD regions. If CTD is physically meaningful, it should be larger over OTs with stronger updrafts.

The BK16 OT detection methods use a set of spatial, statistical, spectral, and pattern recognition analyses designed to mimic the human OT identification process. Their method identifies a set of OT candidates via localized cold spots embedded within convective anvils and assigns an OT probability based on comparisons of local IR $T_{B}$ with the anvil mean $T_{B}$, the tropopause height and temperature, and the regional most unstable equilibrium level. The latter two parameters are defined using NWP or reanalysis data. The texture produced by OTs and gravity waves in VIS imagery is quantified through a unitless "texture rating." The full derivation for VIS texture rating is described in BK16's section 3.2. A VIS texture of 5 typically identifies gravity waves and very weak OTs useful for identifying hazardous aircraft icing conditions (Yost et al. 2018), whereas a rating $>7$ tends to isolate OTs with greater vertical penetration above the anvil. Note that this
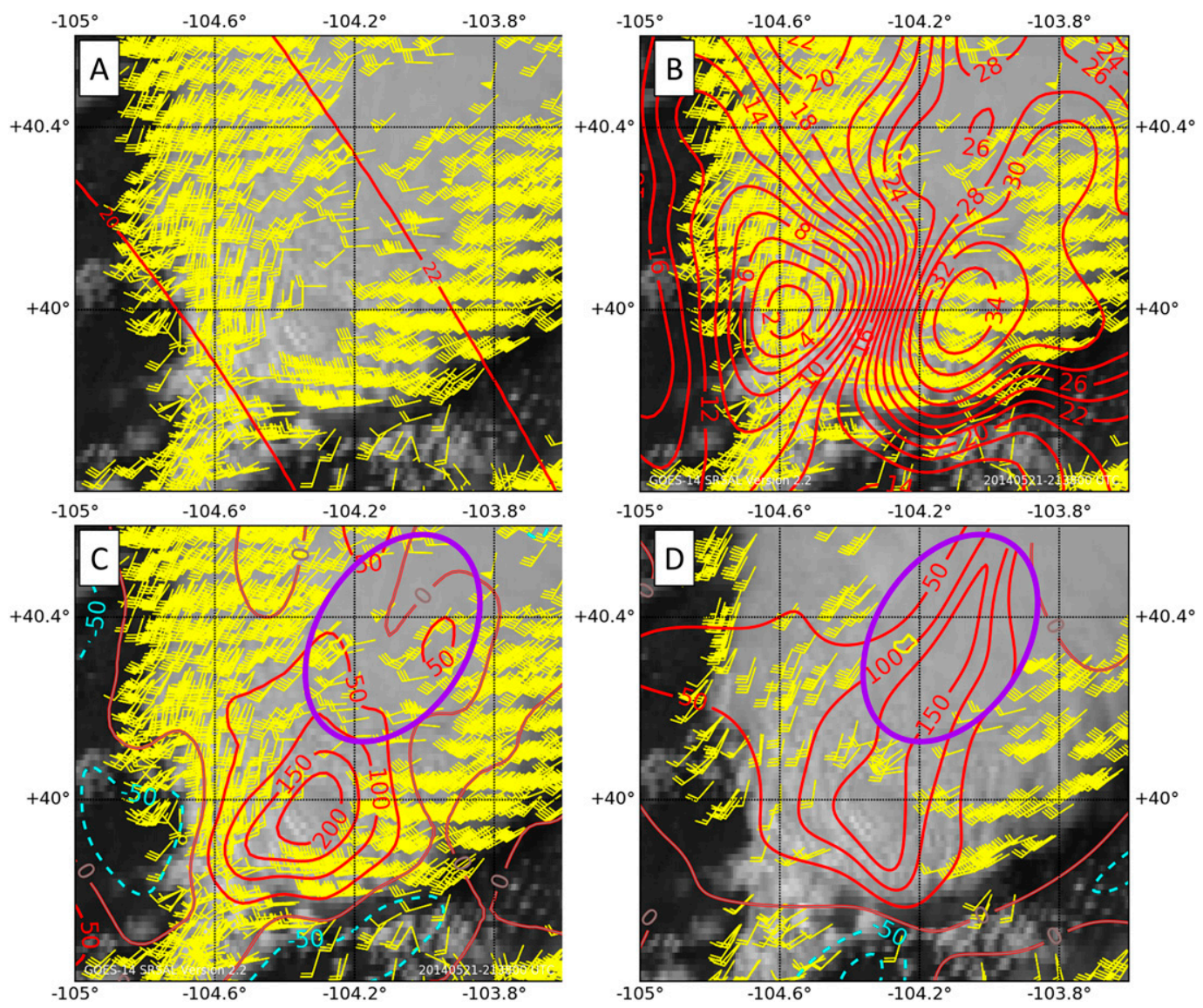

FIG. 1. The 2138 UTC 21 May 2014 GOES VIS imagery along with six sets $(2133,2134,2135,2136,2137$, and 2138 UTC) of derived SRS mAMVs ( $\mathrm{m} \mathrm{s}^{-1} ; 2133-2137$ UTC advected forward to 2138 UTC using GFS storm motion) with (a) the background $u$ field ( $\mathrm{m} \mathrm{s}^{-1}$ ) prior to the final RF analysis pass, (b) the $u$ field ( $\mathrm{m} \mathrm{s}^{-1}$ ) after the final RF analysis pass, (c) the derived CTD contoured every $50 \times 10^{-5} \mathrm{~s}^{-1}$ with positive (negative) divergence values shown in red (blue dash), and (d) the original A16 mAMVs and derived CTD. The purple circle in (c) and (d) highlights an area where CTD was incorrectly interpolated when the mAMV spatial density was low. 
is a daytime-only validation, as the current SRSAL system (and OT VIS texture rating) requires VIS data.

OT detections were tracked through time using the Warning Decision Support System-Integrated Information (WDSS-II) w2segmotionll tool (www.wdssii. org; Lakshmanan et al. 2007). The settings used for w2segmotionll here are shown in Table 2. As suggested in BK16, an OT candidate track that exceeded $50 \%$ probability and a VIS texture rating of 7 was considered an OT detection. These OT tracks were then compared to $40-\mathrm{dBZ}$ echo tops within the case-study domains derived using GridRad. An OT that occurred within $15 \mathrm{~km}$ and $10 \mathrm{~min}$ of a parallax corrected echo top above $7 \mathrm{~km}$ in altitude was considered a "deep OT." Also, OTs within $15 \mathrm{~km}$ and $10 \mathrm{~min}$ of severe weather events from the NCEI database were deemed "severe." For each track, we recorded the track maximum VIS texture rating, OT probability, and CTD near the OT $T_{B}$ minimum.

This analysis also determined if an OT detection was located near local CTD maxima. An OT track was considered a "match" with the nearest CTD maximum if the OT $T_{B}$ minimum was within the region with CTD $>7.5 \times 10^{-4} \mathrm{~s}^{-1}$ and occurred over the same anvil cloud, also objectively identified by the BK16 algorithms. While an anvil may contain multiple OTs, only the OT nearest to a CTD maximum in that anvil was considered a "match." OTs that do not fit these criteria were considered "nonmatches." With the match rate and location differences established, the time evolution of CTD near updrafts was documented during the four individual storms listed above with respect to a variety of indicators of updraft intensity and size characteristics. Two of these storms are highlighted in the following sections.

\section{e. The 18 August 2014 dual-Doppler analysis}

A pulse-type multicell thunderstorm complex occurred near Huntsville, Alabama, within range of the KHTX and ARMOR dual-Doppler domain on 18 August 2014 (the Huntsville Storm). KHTX and ARMOR were quality controlled using the SOLO-III software (Oye et al. 1995) to de-alias radial velocity and remove any second trip echoes and beam artifacts. The edited radar data were mapped to Cartesian (1 km horizontal and vertical spacing) grids using the NCAR RadX 8-point linear interpolation scheme. This scheme has been used in other works such as Kalina et al. (2017) and can be found online (www.ral.ucar.edu/projects/ titan/docs/radial_formats/radx.html). The Custom Editing and Display of Reduced Information in Cartesian Space (CEDRIC; Mohr et al. 1986) system was applied to retrieve three-dimensional flow with the same hydrometeor terminal fall speed relationships and variational mass continuity integration as in Schultz et al. (2015). The maximum updraft speed $\left(w_{\max }\right)$ within the cell was tested
TABLE 2. Settings used in the w2segmotionll system on OT data.

\begin{tabular}{ll}
\hline \multicolumn{1}{c}{ Name } & \multicolumn{1}{c}{ Setting used } \\
\hline Scale 0 & Not used \\
Scale 1 & 1 pixel above $1 \%$ OT probability \\
Tracking type & Multiscale \\
Tracking radius & $2 \times$ the OT size, or within $10 \mathrm{~km}$ \\
Coast frames & 3 frames \\
Age threshold & 30 min \\
\hline
\end{tabular}

for correlation to observed FR, $T_{B}$, and CTD. As this was a single large pulse storm (with one clear maximum in $w$ observed in the time series discussed in section $4 \mathrm{c}$ ), the time-lagged difference between the peak values of $w_{\max }$, $\mathrm{FR}, T_{B}$, and CTD was recorded.

\section{f. The 21 May 2014 Adams County supercell analysis}

The 21 May 2014 (the Adams County, Colorado) supercell (see A16) updraft reached altitudes above the KFTG sampling domain, meaning multi-Doppler variational mass continuity integration necessary to compute a time series of $w_{\max }$ was not possible. Instead, the COLMA total lightning FR measurements were used to infer changes in the updraft size with time. This event, unlike the Huntsville storm, contained multiple strong inferred updraft pulses. FED is used to monitor the spatial extent and location of surges in total lightning and associate those pulses with any temporally related pulses in CTD. We seek to determine if we can see a correspondence between CTD, $T_{B}$, and the inferred updraft size consistent with the Huntsville storm, and if CTD responds to individual updraft pulses affecting the mixed-phase region in both storms, usually highlighted by rapid changes in FR.

\section{Results}

\section{a. OT and CTD comparison}

Statistics summarizing correspondence between OTs and CTD across the four case study events are presented in Table 3. Of the 1182 OT tracks, $\sim 70 \%$ were deep, and $48 \%$ were matches with large CTD maxima within $\sim 13 \mathrm{~km}$ ( $\sim 3$ GOES-14 IR pixels at midlatitudes). There were 566 OTs considered matches with CTD maxima, and $523(\sim 92 \%)$ of these OTs were classified as deep. Increasing the OT probability threshold to $90 \%$ (392 of the OT events) resulted in a $\sim 67 \%$ match rate and a comparable $\sim 13-\mathrm{km}$-average distance difference. From the entire OT sample, matches had a higher-average OT probability and VIS texture rating (Figs. 2a, b). CTD and average OT VIS texture rating were larger for deep OTs than nondeep OTs (Figs. 2c,d). OT tracks without matching large CTD were also found to be 
TABLE 3. Comparison of OTs to CTD with average distance recorded between all positive detections and the nearest located CTD maxima.

\begin{tabular}{|c|c|c|c|c|}
\hline Date & No. of OTs matched & $\begin{array}{c}\text { No. of deep OTs } \\
\text { (No. matched) }\end{array}$ & Total OTs & Distance $(\mathrm{km})$ \\
\hline \multicolumn{5}{|c|}{ OT probability threshold: $50 \%$ VIS rating: 7} \\
\hline 21 May 2014 & 40 & $84(39)$ & 130 & 12.4 \\
\hline 19 May 2015 & 165 & $211(146)$ & 351 & 13.7 \\
\hline 27 May 2015 & 198 & $294(184)$ & 405 & 11.4 \\
\hline 4 Jun 2015 & 163 & $233(154)$ & 296 & 14.6 \\
\hline Total & $566(48 \%)$ & $822(523)$ & 1182 & $\operatorname{Avg}=13$ \\
\hline \multicolumn{5}{|c|}{ OT probability threshold: $90 \%$ VIS rating: 7} \\
\hline 21 May 2014 & 27 & $32(24)$ & 40 & 13.4 \\
\hline 19 May 2015 & 62 & $77(61)$ & 82 & 12.5 \\
\hline 27 May 2015 & 114 & $154(105)$ & 192 & 11.0 \\
\hline 4 Jun 2015 & 58 & $70(57)$ & 78 & 13.2 \\
\hline Total & $261(67 \%)$ & $333(247)$ & 392 & $\operatorname{Avg}=12.5$ \\
\hline
\end{tabular}

approximately one-third of the distance length of tracks with matching large CTD (Table 4). These statistics suggest that the more the updraft protruded above the mean anvil altitude based on satellite IR $T_{B}$ signals, the more likely it was to be deep (i.e., an accurate updraft detection) and have a large CTD. The statistics are similar on a case-by-case basis, with the average distance differences varying by only $1-2 \mathrm{~km}$.

Of the tracks where OTs had matching CTD, 25\% (139) met the severe criteria, while only $\sim 2 \%$ (15) of nonmatching cases were severe (Table 4). CTD and VIS texture rating was greater for severe versus nonsevere OTs (Figs. 2e,f). The median CTD was also larger for severe OTs than deep OTs. Above $8 \times 10^{-4} \mathrm{~s}^{-1} \mathrm{CTD}$, the relative frequency of severe OTs was greater than nonsevere OTs. Likewise, greater relative frequency of deep OTs versus nondeep OTs was observed at and above the lower threshold of $6 \times 10^{-4} \mathrm{~s}^{-1} \mathrm{CTD}$. These statistics are evidence that severe storms, which likely have stronger updrafts than nonsevere storms, contain more prominent and persistent OTs that produce stronger anvil outflow than nonsevere deep OTs. We note that the severe versus nonsevere OT CTD threshold of $8 \times 10^{-4} \mathrm{~s}^{-1}$ was at the 55th (40th) CTD percentile derived for all (deep) OT detections in this SRSAL version.

GOES OT detections that were neither deep nor severe were frequently found in regions of cold-anvil outflow advected downstream from the main updraft or in regions with complex $T_{B}$ that look like OTs in an instantaneous view (Figs. 3a,b). Evaluation of these OTs by the authors indicates that they are commonly found in regions of stratiform precipitation that can feature $T_{B} \mathrm{~S}$ as cold as those found in true OT regions. These false OT patterns downstream of true OTs may form as a result of advection of cold cloud matter from the OT (e.g., shedding; Homeyer et al. 2017), collocation of cold cloud matter to the relatively warm above anvil cirrus plumes, or even local gravity wave breaking (e.g., Wang 2003). OTs deemed nonmatches had low VIS texture ratings and were frequently found around and near above-anvil cirrus plumes. While these may not have been false OT indications, it is noted that, from a nowcasting and observational perspective, a much smaller proportion of these OTs were found with severe weather compared to OTs in the matched sample.

The CTD analyses did, however, miss about a third of the deep OT events. These missed events were frequently associated with small storms $(<\sim 10 \mathrm{~km})$ that may have been excessively smoothed using the RF system parameters described in the appendix. An example is shown in Figs. $3 \mathrm{c}$ and $3 \mathrm{~d}$ where a storm in Oklahoma (which had a narrow 220-K IR area) on 27 May 2015 had distinctly weaker CTD maxima than a tornadic storm (with a broader 220-K IR area) in Kansas to the north, though it did produce large severe hail reports at the ground. We find that $\sim 9.7 \%$ of the severe OTs featured CTD below the $7.5 \times 10^{-4} \mathrm{~s}^{-1}$ threshold. For the DC events that were large enough to be observed, an expected evolution occurred, where CTD increased after DC initiation and decreased after the DC dissipated. That evolution is documented for the following two case studies.

\section{b. The Huntsville storm dual-Doppler analysis}

Three updraft pulses were evident in a time series for the Huntsville storm, a weak updraft at 2000 UTC (labeled as pulse 1 on Fig. 4, top panel), a strong updraft from 2019 to 2107 UTC, which then weakened at 2135 UTC (labeled as pulse 2 on Fig. 4), and a final weak updraft at 2148 UTC. This study focuses on pulse 2 , which 

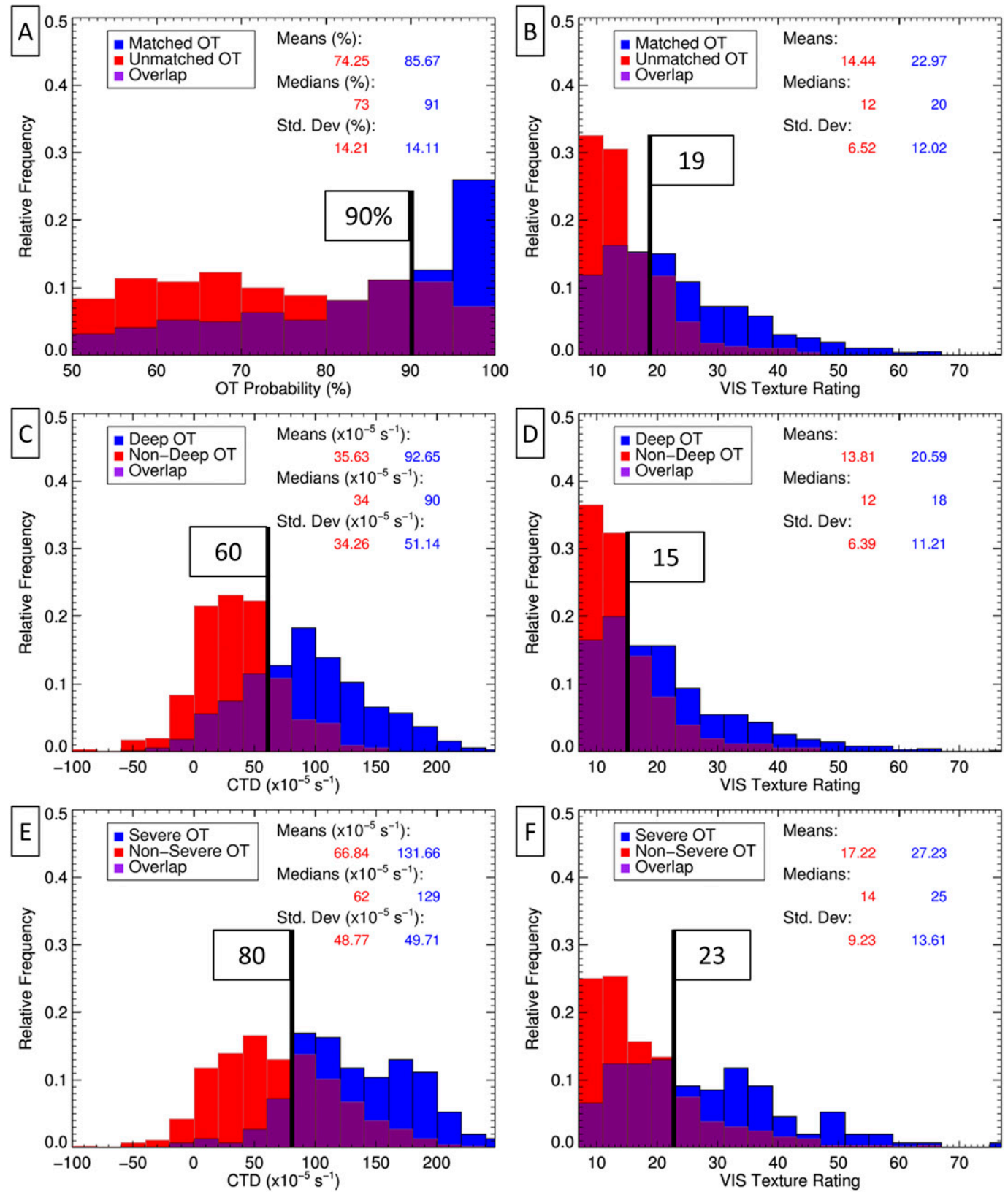

FIG. 2. Relative frequency histograms of (a) deep and nondeep OTs with the maximum OT track CTD at the $T_{B}$ minima and (b) OT average VIS texture rating, (c) matched and unmatched OTs with maximum OT track probability and (d) OT average VIS texture rating, and (e) severe and nonsevere OTs with maximum OT track CTD at the $T_{B}$ minima and (f) OT average VIS texture rating. Flags indicate where relative frequency of matched, deep, and severe OTs were higher than the null detections.

exhibited the characteristics of warm-season, nonsupercell DC. Cooling in the minimum IR $T_{B}$ is the first signal observed as early as 2023 UTC. The first lightning flash associated with this storm is at 2025 UTC, though the FR did not exceed 1 flash $\min ^{-1}$ until 2041 UTC. CTD increased at 2040 UTC as the tropopause relative IR $T_{B}$ approached $\sim 5 \mathrm{~K}$ (nearing the tropopause in height), followed by a derived $w_{\max }$ peak $\left(\sim 24 \mathrm{~m} \mathrm{~s}^{-1}\right)$ at 2100 UTC. The total lightning peaked at 2113 UTC, 4 min after the $\sim 1.75-\mathrm{K}$ tropopause-relative IR $T_{B}$ minimum. CTD peaked at $1.08 \times 10^{-3} \mathrm{~s}^{-1}$ at $2119 \mathrm{UTC}$, after the other three updraft indicators.

CTD, when lagged by $8 \mathrm{~min}$, had a peak correlation of $\sim 0.83$ to smoothed total lightning FR. Unlagged CTD showed a moderate $\sim 0.67$ correlation to $w_{\max }$. The trend 
TABLE 4. Data collected for "matched" OTs (with large CTD maxima) and "nonmatched" OTs (without large CTD maxima) including track length and percentage with severe reports within $10 \mathrm{~min}$ and $15 \mathrm{~km}$ of an OT track.

\begin{tabular}{lcccc}
\hline \hline \multicolumn{4}{c}{ OT thresholds: 50\% VIS rating: 7 } & \\
\hline Date & $\begin{array}{c}\text { Match" OT track } \\
\text { length (km) }\end{array}$ & $\begin{array}{c}\text { "Nonmatch" OT track } \\
\text { length (km) }\end{array}$ & $\begin{array}{c}\text { "Match" OT } \\
\text { severe (\%) }\end{array}$ & $\begin{array}{c}\text { "Nonmatch" OT } \\
\text { severe (\%) }\end{array}$ \\
\hline 21 May 2014 & 16.66 & 4.54 & 15 & 1.1 \\
19 May 2015 & 14.5 & 3.86 & 25.5 & 1.1 \\
27 May 2015 & 6.24 & 1.94 & 28.8 & 2.9 \\
4 Jun 2015 & 6.87 & 2.88 & 20.9 & 4.5 \\
\hline
\end{tabular}

in total lightning (also shown on Fig. 4; top panel) very clearly highlighted pulse 2 , with an increasing trend prior to the updraft maximum, and decreasing trend after the updraft maximum. If we infer this signature in total lightning FR to be indicative of mixed-phase updraft volume variations, we can use it to identify updrafts using only FR data when dual-Doppler information is not available.
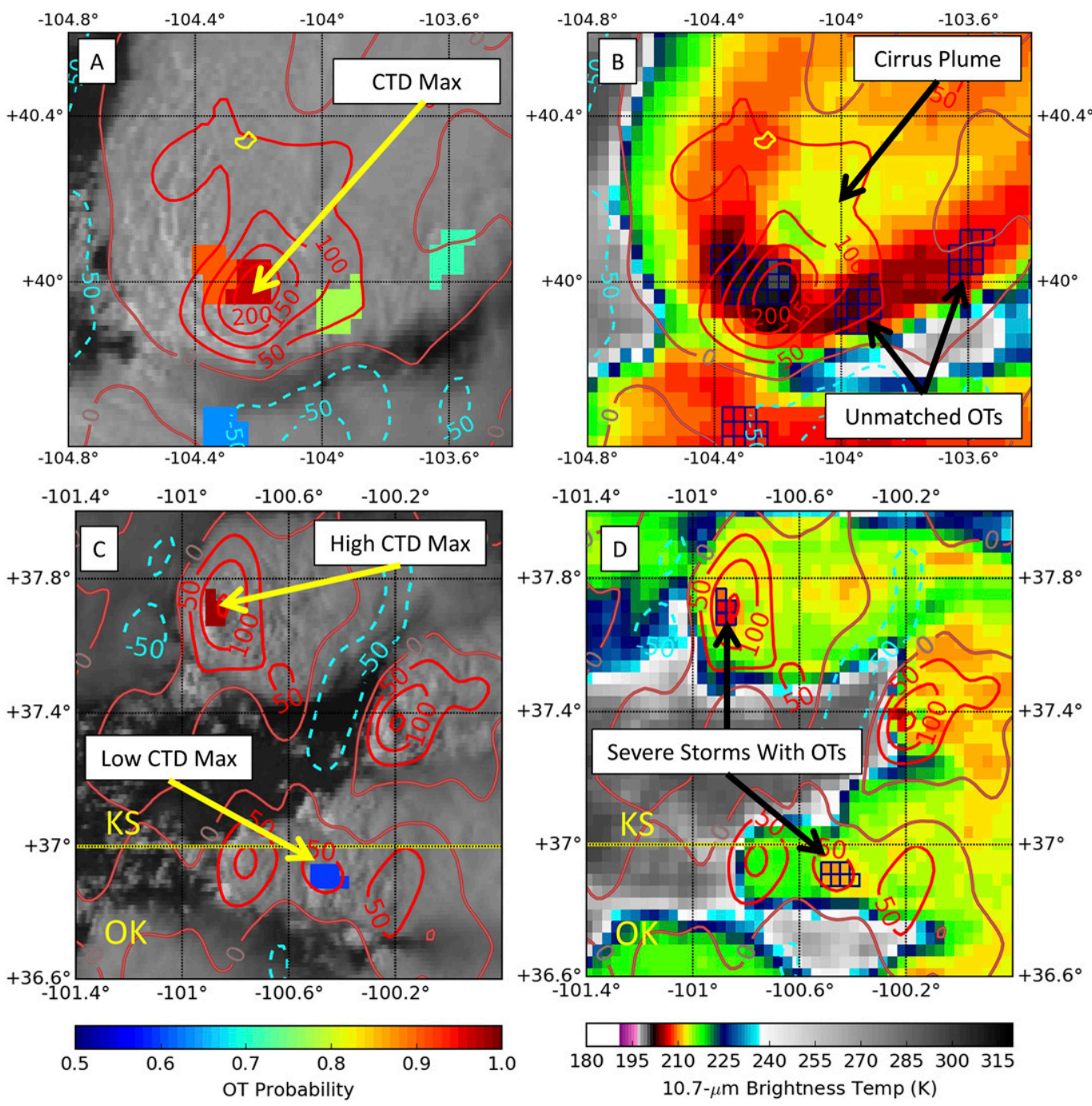

FIG. 3. GOES-14 imagery shown with SRSAL CTD contoured in red every $50 \times 10^{-5} \mathrm{~s}^{-1}$ shown with OT candidates and (a) VIS data for 2217 UTC 21 May 2014 over central Colorado and (b) $10.7-\mu \mathrm{m}$ IR $T_{B}$. (c), (d) As in (a),(b), but for 2220 UTC 27 May 2015 over southern Kansas and northern Oklahoma. 


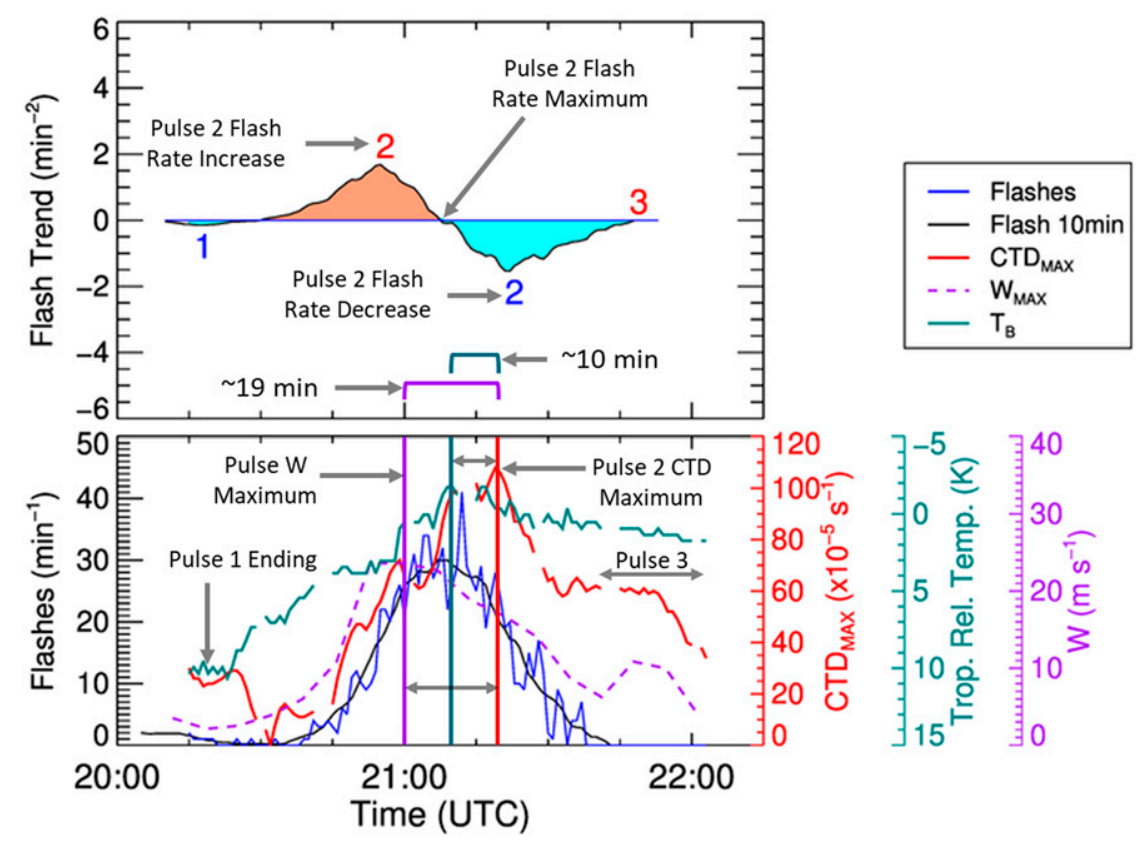

FIG. 4. The Huntsville storm time series of (top) NALMA total lightning 10-min boxcar smoothed FR trend and (bottom) maximum SRSAL CTD magnitude (red line and axis), shown with smoothed FR (black line), unsmoothed FR (blue line), minimum tropopause relative $T_{B}$ (teal line), and $w_{\max }$ (dashed purple line). The numbers in the flash trend indicate the increasing (decreasing) time periods of each identified updraft pulse in red (blue). The vertical lines in the bottom panel indicate the time of the maximum in $w_{\max }$ (purple), minimum $T_{B}$ (teal), and maximum CTD (red).

\section{c. The Adams County supercell analysis}

In the Adams County, Colorado, supercell, we frequently found evidence that CTD was maximized over the locally tallest (and typically strongest) inferred updraft. The evolution of the Adams County supercell is shown here from a satellite (Fig. 5), radar (Fig. 6), and FED perspective (Fig. 7). During the initiation phase of the storm of interest, the CTD maximum was over a different hail-producing storm to the southwest of the Denver International Airport (Fig. 5a; purple arrow in Figs. 6 and 7), and cirrus was obscuring the satellite view of the preconvection initiation cumulus. After the storm reached a higher altitude than the surrounding cirrus, the CTD with this system was detectable in the mAMVs (Fig. 5b). As the storm strengthened and organized, the CTD maximum moved over the weak-echo region at 2005 UTC (Fig. 6) and the lightning hole at 2138 UTC (Fig. 7). We noted at 2138 UTC that, while there were additional apparent updrafts highlighted by FED to the southwest, the CTD maximum was located over what we inferred from FED to be the locally strongest updraft (IR $T_{B}$ is similarly coldest over this region). By 2247 UTC, a new updraft developed near the forward-flank downdraft and CTD waned during this period. The new storm (highlighted by red arrows in Figs. 6, 7) became stronger than the tracked system at 2301 UTC, and rapidly grew upscale with DC to the southeast.

Five individual updraft pulses were evident in the smoothed total lightning time series (Fig. 8, top panel). Only three pulses were found where the correspondence between total lightning FR trends, IR $T_{B}$, and the CTD was clear (red lines in Fig. 8, bottom panel). With these updrafts, we observe some variance among pulses in the timing of the response of CTD to OTs and FR peaks. While pattern shifts in CTD maxima location or magnitude do not fully clarify the CTD response to updraft pulses 2 and 4, it is apparent that CTD did not decrease after major updraft pulses 1 and 3, as was observed with pulse 2 in the Huntsville storm. Without a clear response to updraft pulses 2 and 4 , the correlation between FR and CTD was very weak $(\sim 0.38)$ while CTD was above the $7.5 \times 10^{-4} \mathrm{~s}^{-1}$ threshold (from 1945 to 2300 UTC). No obvious relationship exists between the timing of CTD responses to updraft pulses and tornado occurrences (though CTD is large during most of the events). Hail diameter appeared more responsive than tornadoes to CTD changes, particularly $\sim 18 \mathrm{~min}$ after pulse 3 , where reported hail diameter increases from $\sim 2.54$ to $4.45 \mathrm{~cm}$.

While a linear relationship was not observed between FR and CTD with this storm, if we combine this case 

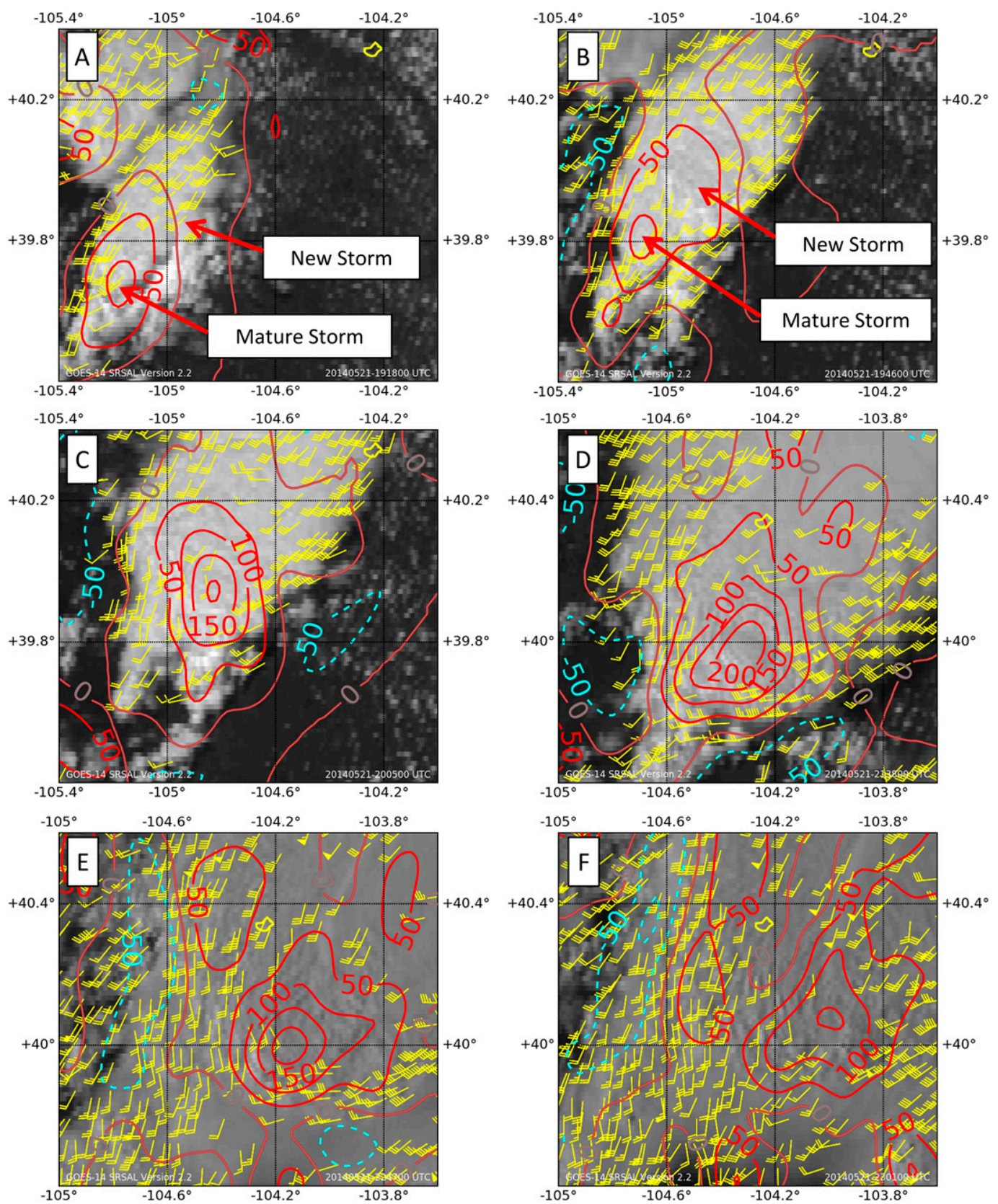

FIG. 5. The 21 May 2014 Adams County supercell SRSAL CTD contoured every $25 \times 10^{-5} \mathrm{~s}^{-1}$ with positive (negative) shown in red (blue dash) centered over the supercell of interest with one out of six sets of mAMVs used for CTD derivation (yellow barbs; $\mathrm{m} \mathrm{s}^{-1}$ ) and GOES-14 VIS imagery for (a) 1918, (b) 1946, (c) 2005, (d) 2138, (e) 2247, and (f) 2301 UTC.

study's total lightning and CTD findings with tracked Hale County and Elbert County supercells, it becomes evident that higher total lightning FRs are observed in storms containing higher CTD (Fig. 9). The lower FRs (from 0 to $\left.20 \mathrm{~min}^{-1}\right)$ had higher CTD variance $\left(\sim 0.038 \mathrm{~s}^{-2}\right)$ than higher observed FRs $\left(60-80 \mathrm{~min}^{-1}\right.$ had a $\sim 0.015 \mathrm{~s}^{-2}$ CTD variance). This plot suggests that strong updrafts with very high FRs have a higher likelihood of producing observable CTD, while weaker updrafts with lower flash rates may not always be evident at cloud top (hence the higher variance in CTD).

\section{Discussion}

The guiding hypothesis is that if CTD is appropriately derived over DC at the storm scale $(<20 \mathrm{~km})$, then CTD 

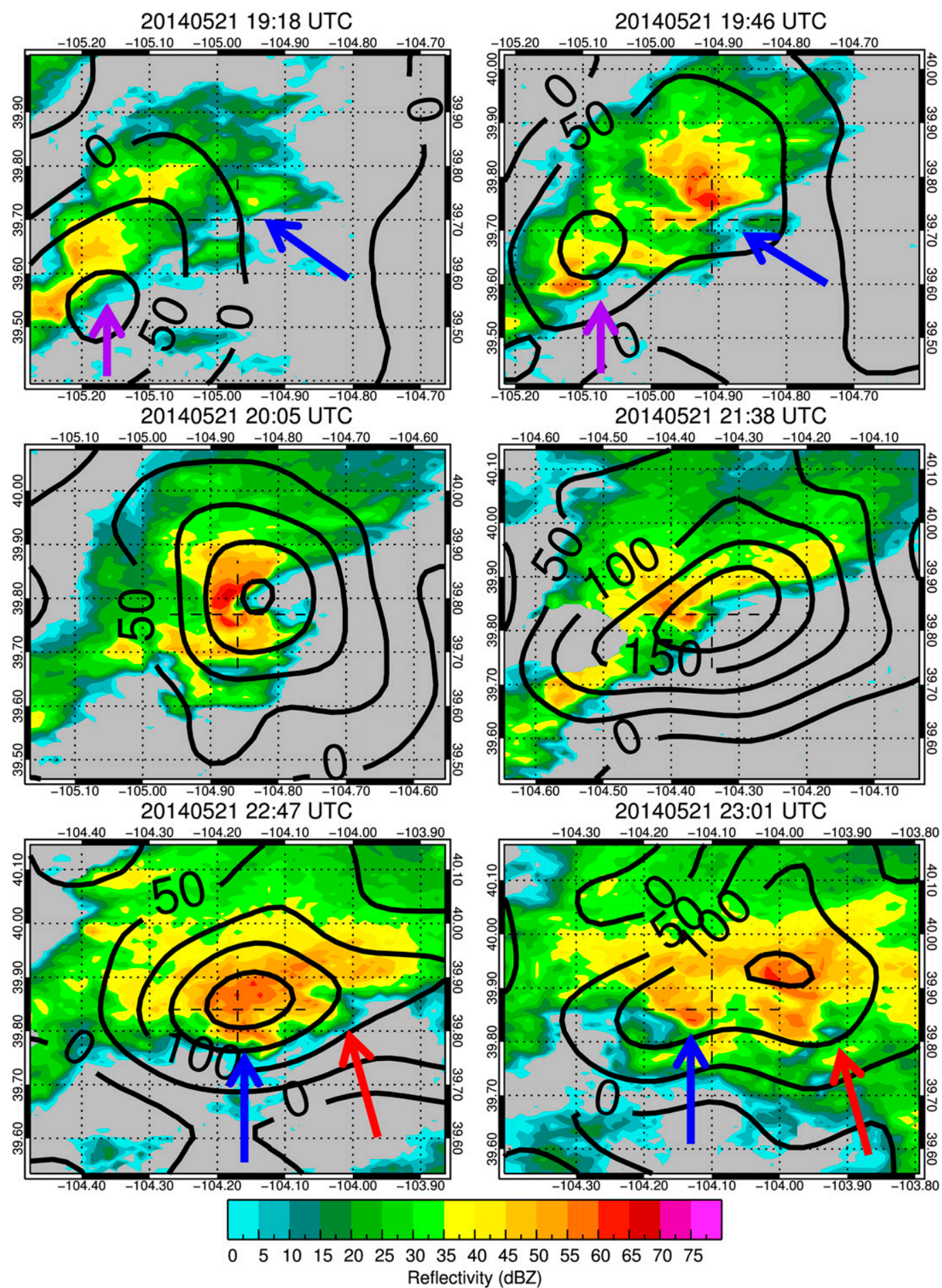

FIG. 6. The 21 May 2014 Adams County supercell $4 \mathrm{~km}$ constant-altitude plan position indicator views of radar $Z_{H}$ from KFTG in central Colorado centered on the supercell of interest at the same times as in Fig. 5 with parallaxcorrected SRSAL CTD contoured in black every $50 \times 10^{-5} \mathrm{~s}^{-1}$. The blue arrow highlights the supercell of interest, and the purple and red arrows highlight additional updrafts near the supercell of interest. 

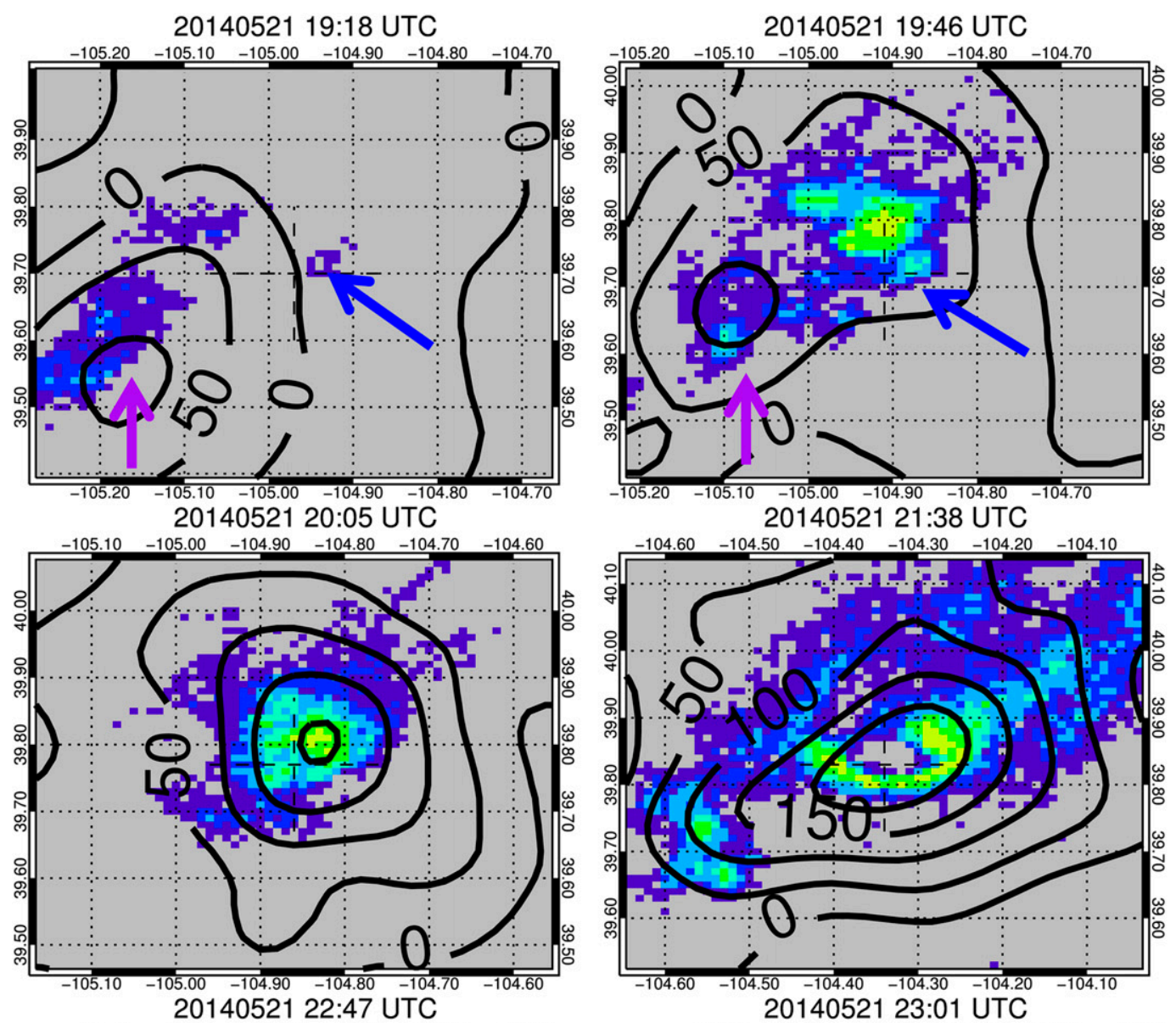

$2014052123: 01$ UTC
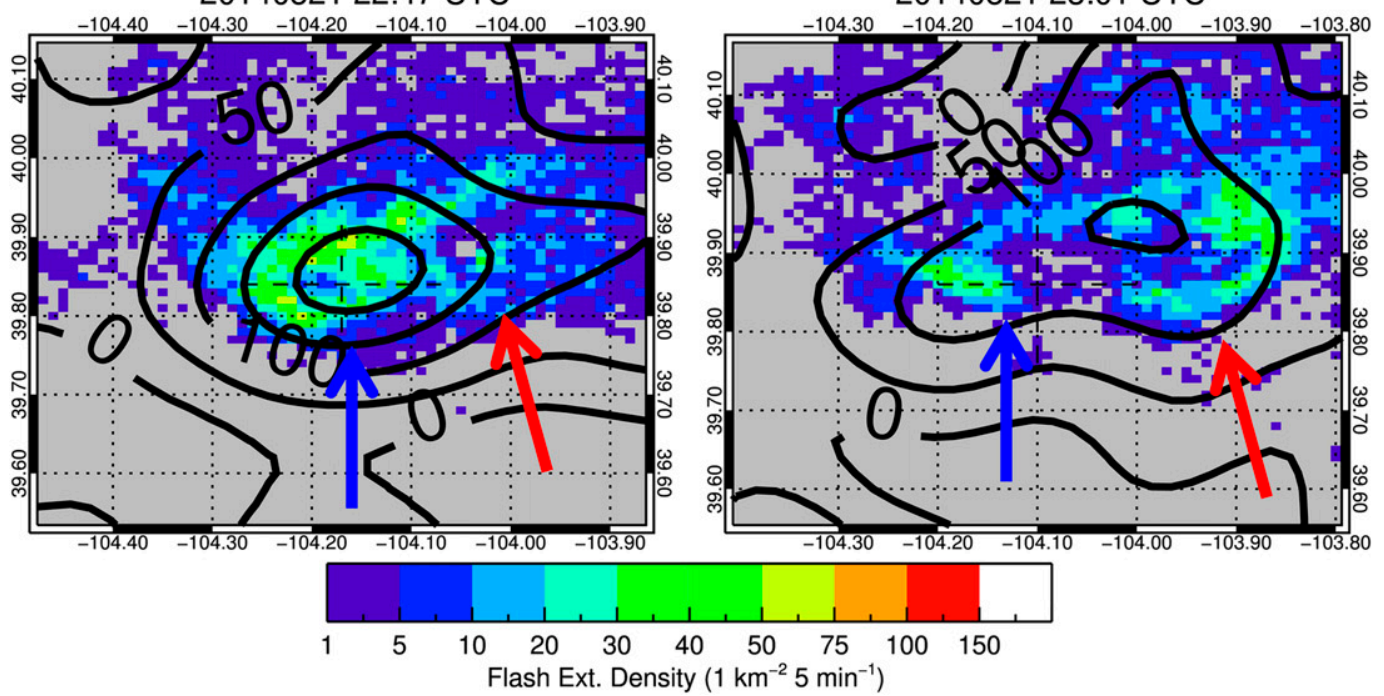

FIG. 7. As in Fig. 6, but with COLMA measured FED instead.

will peak spatially near objectively identified OTs, and the CTD maximum will be correlated to internal and nearstorm-top updraft characteristics, such as updraft volume, $w_{\max }$, and lightning FRs. The results presented show evidence that OTs occur within three IR pixels of large CTD, though the CTD maxima are not necessarily correlated in time to the inferred updraft volume (based on FR) for all cases. CTD maxima did, however, appear to be larger in the presence of stronger updrafts, though only the locally tallest, noncirrus obscured updrafts are observed. 


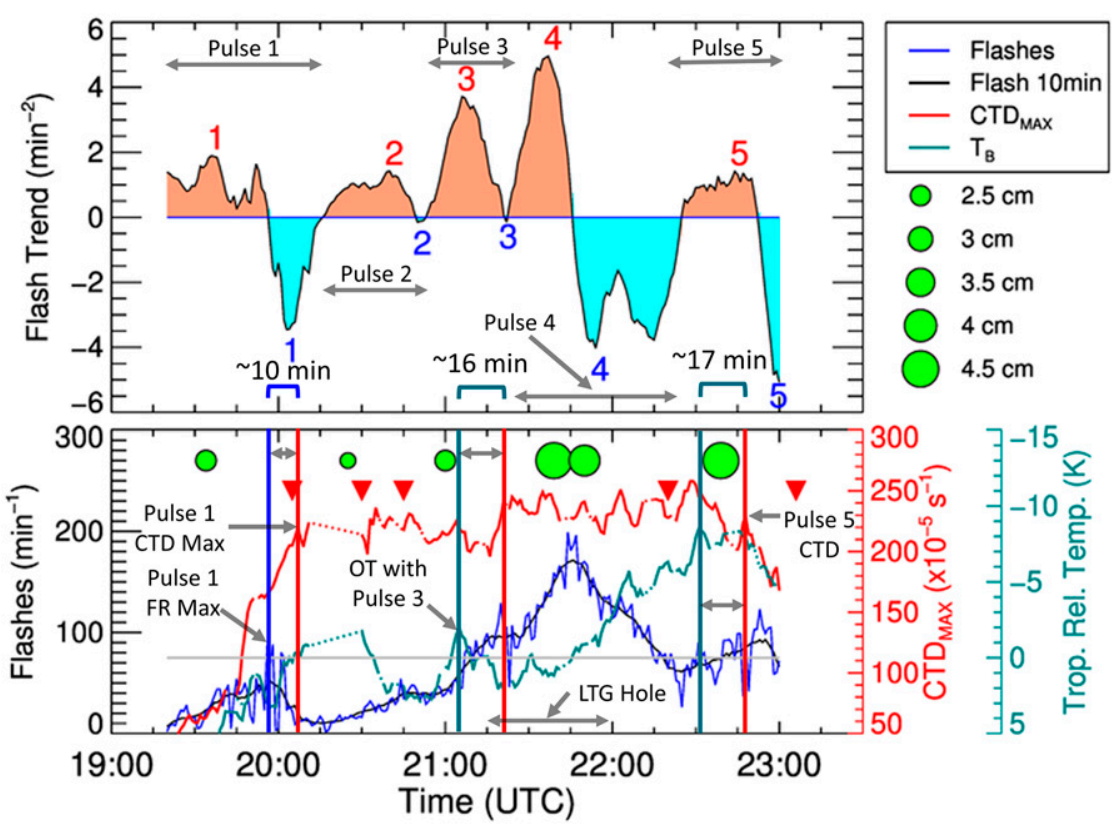

FIG. 8. The 21 May 2014 Adams County supercell storm time series of (top) COLMA total lightning 10-min boxcar smoothed FR trend, shown with smoothed FR (black line), unsmoothed FR (blue line), maximum SRSAL CTD (red line and axis), and minimum tropopause relative $T_{B}$ (olive line). The numbers in the flash trend indicate the increasing (decreasing) time periods of each identified updraft pulse in red (blue). The vertical lines indicate the time of the maxima in FR (blue), minima in $T_{B}$ (olive), and maxima in CTD (red). Also shown are times of hail reports (green circles) and tornado reports (red triangles) at the ground.

Some spatial displacement between SRSAL CTD maxima and OT locations was expected. Algorithm development issues covered in A16 and BK16 aside, we expect that storm-scale CTD likely occurs after (and perhaps downstream from where) an OT is observed, as it would take time for a small $\sim 4 \mathrm{~km}$ OT to descend and expand radially to limits sufficiently detectable by SRSAL above $\sim 10 \mathrm{~km}$ in horizontal extent. The delay in CTD is similar to issues in radar anvil-reflectivity-based algorithms for determining the level of maximum detrainment in DC, which require anvil-level hydrometeors to develop prior to robust detection (e.g., Carletta et al. 2016; see section 4c). When coupled with storm motion, this delay is likely to result in some enhanced CTD maxima displacement from OTs. However, there were times in the Adams County supercell where CTD existed without OT detections (not shown). Thus, an OT does not have to be present for enhanced outflow to occur.

The inference that CTD is larger for stronger updrafts is supported by using higher probability (and VIS texture rating) thresholds from the BK16 OT system, as a higher percentage of more deeply protruding OTs in all case studies were found near large CTD. The OT probabilities and VIS texture ratings were both designed to detect more deeply protruding updrafts, so the higher the probability, the taller (and inferred stronger) the updraft. We also found that OTs with higher CTD $\left(>8 \times 10^{-4} \mathrm{~s}^{-1}\right)$ and OT VIS texture ratings were indicative of updrafts from severe weather-producing storms. The explanation behind these results is that larger (in diameter and amplitude) and temporally persistent updrafts are more likely to produce detectable cloud-top outflow with SRSAL, and thus OTs found within that detectable outflow were more likely to be severe. These CTD and OT VIS texture rating magnitudes were found for storms containing any reported severe weather occurrence and may change depending on the differences in the degree of severity. The CTD median value for all deep OTs was lower than that for severe OTs, which implies that the severe OTs have, on average, stronger inferred updrafts than OTs that are merely deep.

So, if CTD is larger for severe versus nonsevere OTs, and higher for deep versus nondeep OTs, should there be a linear relationship between derived CTD and updraft strength and volume? Deierling and Petersen (2008) stated that the mixed-phase updraft volume exhibited very strong correlations with the total lightning FRs in storms. If we assume that CTD is correlated to the mixed-phase updraft volume, then our findings here would be inconsistent with the previous total lightning 


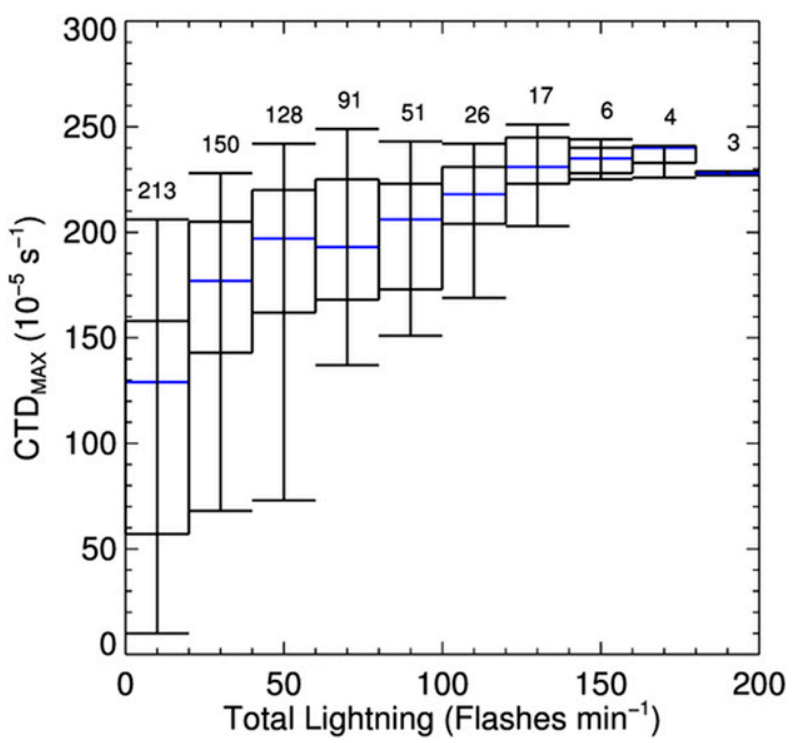

FIG. 9. Box-and-whisker plots of the derived max CTD percentiles in 20 flashes min $^{-1}$ FR bins for the 21 May 2014 (the Adams County supercell), 27 May 2015 (the Hale County supercell), and 4 June 2015 (the Elbert County supercell) storms. Each of the boxand-whisker plots represents the 5th, 25th, 50th, 75th, and 95th percentile of max CTD during which the tracked storms had a flash rates from $0-19,20-39,40-59$ flashes $\min ^{-1}$, etc. The sample size from the three storms for each bin is shown above the 95th percentile. Blue lines indicate the location of the median for each FR bin.

FR studies. It is conceivable that processes that hinder noninductive charging mechanisms affected the total lightning relationship to updraft strength, for example, wet hail growth (Emersic et al. 2011). However, the low correlation between CTD and FR is likely in part due to errors in the satellite flow observations. For example, SRSAL CTD only reflects the updraft (and subsequent diverging cloud material) that reaches the cloud top, and not necessarily the internal mixed-phase updraft volume inferred by total lightning. To some extent, then, we wonder if there could be observational value in determining which updraft pulses are reflected at the cloud top, and how that relates to cloud electrification and severe weather. Previous studies (A16; BK16) suggest that the locally strongest updraft would generate the largest CTD signature, highest OT VIS texture rating, and highest OT probability, and indeed OTs with higher values of all three of these parameters were found more likely to be severe than OTs without. This is supported by the observation that the largest CTD maximum occurred nearest to the BWER and total lightning FED hole in the Adams County supercell. Thus, applying CTD with other metrics for nowcasting could help to identify the strongest updrafts in a local region and adjust severe weather probabilities accordingly.

There are a few other sources of error from the satellite flow-derivation standpoint that may have impacted the findings here. Currently, even with the enhancements added to the targeting and objective analysis approach, minimum SRSAL feature resolution is still $\sim 10 \mathrm{~km}$, thus the derived CTD magnitude is well below the actual cloud-top outflow value, which may well be more closely related to FR measurements. Tests with different forms of AMV computation, such as optical flow (Bresky and Daniels 2006; Wu et al. 2016) may also improve gridded flow spatial resolution over DC. We also must investigate above-anvil cirrus plumes generated through gravity wave breaking (e.g., Wang 2003) in environments with strong upper-troposphericlower-stratospheric-level storm-relative flow (Homeyer et al. 2017) that may act to reduce derived CTD within the "flat plane" assumption used in the A16 method. Improved cloud-height assignment algorithms with a multilevel SRSAL system (one that performs an RF in separate pressure and altitude layers) will likely reduce the cloud-top cirrus impact and cloud-edge vector contamination (where low-level vectors at a cumulonimbus cloud edge are mistakenly assigned altitudes near the cloud top).

The reader should note the sample size here is relatively small (conforming to the availability of DC in the GOES-14 SRS collections over the Great Plains), and a larger sample size with GOES-16 may yield different relationships of CTD and OTs to severe weather occurrence. For example, most severe wind reports originate from mesoscale convective systems, which seldom exhibit large and long-lived OTs as prominent as discrete supercells. Thus, skill scores (e.g., probability of detection and false alarm ratio) of CTD nowcasting systems may vary when validating a large sample of distinct types of severe weather. CTD and OTs before and during severe weather likely also vary by season and region. It will also be important to analyze the impact of the convective environment on a large sample of CTD and OT occurrences, and how that might change the performance of any developed nowcasting systems. For example, environments with weaker stability above the tropopause may yield deeper OTs with weaker CTD, yet the production of severe weather at the ground may be unchanged. Real-time NWP estimations of convective environments, used with CTD and OTs, could then improve any new nowcasting schemes developed in the future.

\section{Conclusions}

A new RF approach was applied to derive storm-scale flow fields with SRS satellite mAMVs over DC. Derived CTD from these flow fields was compared to radar, total lightning signatures, objectively identified OTs, and dual-Doppler radar signatures to observe how well the flow system characterized updraft location and intensity 
for storms. The primary findings of this study are as follows:

- About $48 \%$ of automated OT detections were found with matching large $\left(>7.5 \times 10^{-4} \mathrm{~s}^{-1}\right)$ CTD maxima. OT $T_{B}$ minima and CTD maxima locations match closely (within $\sim 13 \mathrm{~km}$ ) for storms observed here. OTs with matching large CTD over DC were more frequently associated with precipitation and severe weather at the ground, while OTs without large CTD were lower in OT probability and OT VIS texture rating and shorter in track length, suggesting that many of the latter OT detections were not linked to actual updrafts. OTs with a higher probability and higher VIS texture rating were also more likely to be associated with large CTD.

- The sample of OTs with CTD $>8 \times 10^{-4} \mathrm{~s}^{-1}$ (55th percentile of maximum CTD derived at OT $T_{B}$ minima) and high OT VIS texture rating had a higher relative severe weather occurrence frequency than OTs with CTD below this threshold.

- About $92 \%$ of OT detections matched with large CTD were associated with $40-\mathrm{dB} Z$ echo tops above $7 \mathrm{~km}$ from ground-based radar (assumed to be indicative of DC here). SRSAL CTD, in total, identified $64 \%$ of all deep OTs sampled here.

- A high correlation was observed between CTD and total lightning FR for a nonsupercell single-pulse storm (with an 8-min lagged $\sim 0.83$ correlation coefficient).

- The relationship between CTD and the total lightning for the supercell storm was weaker than the nonsupercell thunderstorm, with an observed $\sim 0.38$ correlation. Evidence was shown that only the tallest (strongest) updraft pulses were reflected at the cloud top, meaning some of the pulses were not seen with corresponding CTD.

- Despite the complexity of the relationship between total lightning and derived CTD for the mature supercell, higher FRs were generally found in periods with larger CTD.

As shown here, CTD should not be used alone to identify DC and internal updraft intensification (in terms of updraft magnitude and volume). Derived CTD only identified about two-thirds of observable DC in this sample. It was also not correlated to total lightning FR when multiple updrafts of varying magnitude were present (as in the Adams County supercell). However, the results presented in the bullets above imply that the mAMV-derived system is outputting more than noise from the imagery. When used with OTs, CTD can help a forecaster identify the primary updrafts of storms. The CTD intensity may also improve identification of severe versus nonsevere DC, though higher CTD thresholds for matched OTs should be for this purpose (only $25 \%$ of matched OTs were severe here). The late development of CTD in DC implies that lead time for severe weather nowcasting would not be added by using CTD over $T_{B}$ or total lightning FR. CTD instead can be utilized as a separate yet complementary interest field to overcome deficiencies present in $T_{B}$ cooling and total lightning FR detection. For added lead time, the CTD time trend should be used, as large increases of CTD precede temporal maxima by several minutes.

From here, a multivariate statistical approach for quantifying updraft characteristics of DC using SRSAL CTD should be used, since CTD can be a function of environmental variables. Furthermore, $w$ is related to the three-dimensional divergence profile, and while one divergence level may be correlated to this change, it does not capture the entire mesoscale overturning process. Future experiments with GOES-16 can combine parallax-corrected CTD with local radar data for a better implied ascent estimate using observations throughout the entire depth of a column in DC. Multilayer cloud environments with large vertical wind shear and incorrect mAMV height assignments that may introduce noise into the flow field derivations should also be explored more thoroughly with stereoscopic height analysis (e.g., Fujita 1982) upon the launch of newer GEO satellites such as GOES-17. Validation tests with AMV-related observing system simulation experiments may also ensure the correct cloud-top outflow quantification (when the actual motion of an observed target and updraft strength of an observed storm can be quantified).

Acknowledgments. This study was funded under the National Science Foundation Grant AGS-1261368 and NASA Grant NNX15AV82G. We extend our gratitude to Dr. Steven Rutledge at Colorado State University, Dr. Eric Bruning at Texas Tech University, Dr. Dan Lindsey from the Cooperative Institute for Research in the Atmosphere, and Dr. Larry Carey at the University of Alabama in Huntsville, for providing the data necessary for completing this study. We also would like to thank Chris Velden and David Stettner at the Space Science and Engineering Center in Madison, Wisconsin, for their input on $\mathrm{mAMV}$ derivation. We would also like to thank Dr. Jim Purser at the National Oceanic and Atmospheric Administration for helpful comments on using the recursive filter analysis.

\section{APPENDIX}

\section{Recursive Filter Analysis Description}

The RF system is an empirical linear interpolator with a spatially varying scale based on the nearby pointsource observation density and quality (assigned using the weighted deviation from background flow). In one 
TABLE A1. Descriptions of RF parameters used in SRSAL, version 2.2, with notation from Hayden and Purser (1995), where the asterisk means the same value is used throughout the analysis pass.

\begin{tabular}{lcc}
\hline \hline \multicolumn{1}{c}{ RF parameter } & $\begin{array}{c}\text { Initial background analyses: Analysis } 1, \\
\text { analysis } 2\end{array}$ & Final analysis (final pass setting) \\
\hline Grid increment $\delta$ & $\sim 2 \mathrm{~km}\left(0.02^{\circ} \mathrm{N} \times 0.02^{\circ} \mathrm{W}\right),{ }^{*}$ & $*$ \\
Smoothness degree $f$ & $1,0.7$ & $1,(0.5)$ \\
Tolerance $T$ & $99999 \mathrm{~m} \mathrm{~s}^{-1}, 25 \mathrm{~m} \mathrm{~s}^{-1}$ & $25 \mathrm{~m} \mathrm{~s}^{-1}$ \\
Smoothing iterations per analysis pass $L$ & 10,3 & 3 \\
No. of RF analysis passes & 1,5 & 5 \\
Initial characteristic scale $R_{0}$ & $\sim 111 \mathrm{~km}, \sim 666 \mathrm{~km}$ & $8 \delta$ \\
Final characteristic scale $R_{\infty}$ & $\sim 111 \mathrm{~km}, *$ & $5 \delta$ \\
Nominal scale and tolerance change rate $s$ & $0.36, *$ & $*$ \\
Background field relative weight & 0,0 & 0.01 \\
Observation weight $W$ & 1,1 & 1 \\
\hline
\end{tabular}

dimension, the RF is defined with forward smoothing operation as

$$
A_{i}^{\prime}=\alpha A_{i-1}^{\prime}+(1-\alpha) A_{i}
$$

and a backward smoothing operation as

$$
A_{i}^{\prime \prime}=\alpha A_{i+1}^{\prime \prime}+(1-\alpha) A_{i}^{\prime},
$$

where $i$ is the integer index value of a grid point to be analyzed; $A_{i}^{\prime}$ and $A_{i}^{\prime \prime}$ represent the forward and backward smoothed output from the RF, respectively; $A_{i}$ is the initial background grid field, which can begin as background model data or a point source estimate of the initial scalar variable and be replaced by successive analysis fields through multiple applications of Eqs. (A1) and (A2); and $\alpha$ is the RF scaling parameter, which varies as a function of successive pass, point-source density, and data quality, and ranges from $0<\alpha<1$. The mAMVs height assigned above 500-hPa altitudes are initially interpolated to this grid using the adjoint of a linear interpolation operator assuming they all exist on one flat, twodimensional plane. Equations (A1) and (A2) are then applied successively in $x$ and $y$ dimensions with boundary conditions to simulate infinitely long grids [following Appendix A of Hayden and Purser (1995)].

The successive application of both Eqs. (A1) and (A2) initially generates a heavily smoothed scalar field, and recovers finer and finer detail with each additional analysis pass. Varied scaling removes artifacts observed in A16, specifically large phase and amplitude distortions of an objectively analyzed scalar caused by grid points being overly influenced by one observation, by increasing smoothing toward background data where point-source observed data spatial density is low. To determine $\alpha$ at each successive pass, the RF system has various subjective tunable features, which are summarized in Table A1.
Using the variables defined in Table A1 with the spectral response function in Purser and McQuigg's (1982) Eq. (12), it is found that the RF analysis final pass here yielded finer wavelength flow features that could not be identified by the original A16 Barnes implementation (Fig. A1, black line). This improved resolving power is an important advancement that is highly relevant to the storm-scale analyses presented in this study. The RF settings used in Table A1 resulted in a maximum possible feature resolution of $\sim 10 \mathrm{~km}$ (the red line in Fig. A1), though the smoothing of wavelengths finer than $10 \mathrm{~km}$ can be reduced by decreasing the final characteristic spatial-scale limit on the final

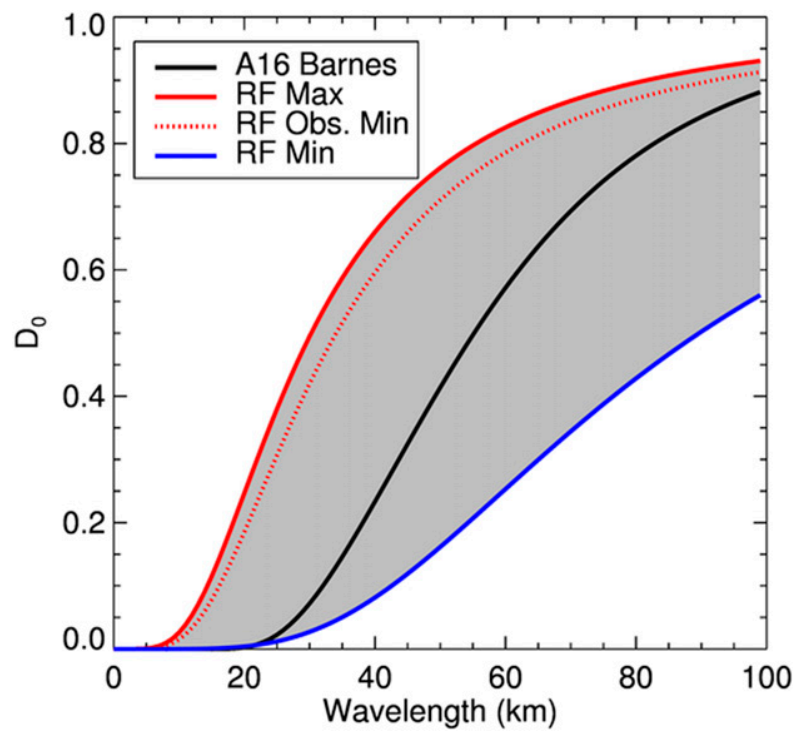

FIG. A1. RF analysis spectral response function $\left(D_{0}\right)$ as a function of wavelength showing the RF system theoretical upper limit (solid red line) and the lower boundary minimum (solid blue line) with the range of possible smoothing values shown in gray. Also shown is the maximum overall observed value (red vertical dash) and the A16 original Barnes analysis spectral response function (solid black line). 
analysis (setting $R_{\infty}$ in Table A1) as the vector spatial density improves with GOES-16 imagery. The smoother response (from larger values of $\alpha$; the blue line indicated in Fig. A1) of the RF analysis occurred at grid points where few mAMVs existed within close $(\sim 10 \mathrm{~km})$ proximity (e.g., where there were no clouds to produce mAMVs). Flow fields with dense mAMV observations peaked at $\alpha=0.405$ (represented by the red dashed line in Fig. A1).

\section{REFERENCES}

Apke, J. M., J. R. Mecikalski, and C. P. Jewett, 2016: Analysis of mesoscale atmospheric flows above mature deep convection using super rapid scan geostationary satellite data. J. Appl. Meteor. Climatol., 55, 1859-1887, https://doi.org/10.1175/ JAMC-D-15-0253.1.

Bedka, K. M., and J. R. Mecikalski, 2005: Application of satellitederived atmospheric motion vectors for estimating mesoscale flows. J. Appl. Meteor., 44, 1761-1772, https://doi.org/10.1175/ JAM2264.1.

__ , and K. Khlopenkov, 2016: A probabilistic multispectral pattern recognition method for detection of overshooting cloud tops using passive satellite imager observations. J. Appl. Meteor. Climatol., 55, 1983-2005, https://doi.org/ 10.1175/JAMC-D-15-0249.1.

—, C. S. Velden, R. A. Petersen, W. F. Feltz, and J. R. Mecikalski, 2009: Comparisons of satellite-derived atmospheric motion vectors, rawinsondes, and NOAA wind profiler observations. J. Appl. Meteor. Climatol., 48, 1542-1561, https://doi.org/10.1175/2009JAMC1867.1.

, J. Brunner, R. Dworak, W. Feltz, J. Otkin, and T. Greenwald, 2010: Objective satellite-based detection of overshooting tops using infrared window channel brightness temperature gradients. J. Appl. Meteor. Climatol., 49, 181-202, https://doi.org/ 10.1175/2009JAMC2286.1.

— , R. Dworak, J. Brunner, and W. Feltz, 2012: Validation of satellite-based objective overshooting cloud-top detection methods using CloudSat cloud profiling radar observations. J. Appl. Meteor. Climatol., 51, 1811-1822, https://doi.org/ 10.1175/JAMC-D-11-0131.1.

, C. Wang, R. Rogers, L. D. Carey, W. Feltz, and J. Kanak, 2015: Examining deep convective cloud evolution using total lightning, WSR-88D, and GOES-14 super rapid scan datasets. Wea. Forecasting, 30, 571-590, https://doi.org/10.1175/ WAF-D-14-00062.1.

— E. Murillo, C. R. Homeyer, B. Scarino, and H. Mersiovski, 2018: The above anvil cirrus plume: An important severe weather indicator in visible and infrared satellite imagery. Wea. Forecasting, 33, 1159-1181, https://doi.org/10.1175/WAF-D-180040.1.

Blair, S. F., D. R. Deroche, J. M. Boustead, J. W. Leighton, B. L. Barjenbruch, and W. P. Gargan, 2011: A radar-based assessment of the detectability of giant hail. Electron. J. Severe Storms Meteor., 6 (7), http://www.ejssm.org/ojs/index.php/ ejssm/article/viewArticle/87.

Boustead, J. M., 2008: Using maximum storm-top divergence and the vertical freezing level to forecast hail size. 24th Conf. on Severe Local Storms, Savannah, GA, Amer. Meteor. Soc., P6.6, https:// ams.confex.com/ams/pdfpapers/142145.pdf.

Bresky, W. C., and J. Daniels, 2006: The feasibility of an optical flow algorithm for estimating atmospheric motion. Proc.
Eighth Int. Winds Workshop, Beijing, China, EUMETSAT, 24-28.

,-- A. A. Bailey, and S. T. Wanzong, 2012: New methods toward minimizing the slow speed bias associated with atmospheric motion vectors. J. Appl. Meteor. Climatol., 51, 21372151, https://doi.org/10.1175/JAMC-D-11-0234.1.

Bruning, E., N. Wang, R. Albrecht, and K. Gopalan, 2011: A Lightning Mapping Array for West Texas: Deployment and research plans. Fifth Conf. on Meteorological Applications of Lightning Data, Seattle, WA, Amer. Meteor. Soc., 6.2, https://ams.confex. com/ams/91Annual/webprogram/Paper184224.html.

Brunner, J. C., S. A. Ackerman, A. S. Bachmeier, and R. M. Rabin, 2007: A quantitative analysis of the enhanced-V feature in relation to severe weather. Wea. Forecasting, 22, 853-872, https://doi.org/10.1175/WAF1022.1.

Carletta, N. D., G. L. Mullendore, M. Starzec, B. Xi, Z. Feng, and X. Dong, 2016: Determining the best method for estimating the observed level of maximum detrainment based on radar reflectivity. Mon. Wea. Rev., 144, 2915-2926, https://doi.org/ 10.1175/MWR-D-15-0427.1.

Cooney, J. W., K. P. Bowman, C. R. Homeyer, and T. M. Fenske, 2018: Ten year analysis of tropopause-overshooting convection using GridRad data. J. Geophys. Res. Atmos., 123, 329-343, https://doi.org/10.1002/2017JD027718.

Crum, T. D., and R. L. Alberty, 1993: The WSR-88D and the WSR88D operational support facility. Bull. Amer. Meteor. Soc., 74, 1669-1687, https://doi.org/10.1175/1520-0477(1993)074<1669: TWATWO $>2.0 . \mathrm{CO} ; 2$.

Deierling, W., and W. A. Petersen, 2008: Total lightning activity as an indicator of updraft characteristics. J. Geophys. Res., 113 , D16210, https://doi.org/10.1029/2007JD009598.

Emersic, C., P. L. Heinselman, D. R. MacGorman, and E. C. Bruning, 2011: Lightning activity in a hail-producing storm observed with phased-array radar. Mon. Wea. Rev., 139, 18091825, https://doi.org/10.1175/2010MWR3574.1.

Frame, J., P. Markowski, Y. Richardson, J. Straka, and J. Wurman, 2009: Polarimetric and dual-Doppler radar observations of the Lipscomb County, Texas, supercell thunderstorm on 23 May 2002. Mon. Wea. Rev., 137, 544-561, https://doi.org/10.1175/ 2008MWR2425.1.

Fujita, T. T., 1981: Tornadoes and downbursts in the context of generalized planetary scales. J. Atmos. Sci., 38, 15111534, https://doi.org/10.1175/1520-0469(1981)038<1511: TADITC $>2.0 . \mathrm{CO} ; 2$.

_ 1982: Principle of stereoscopic height computations and their applications to stratospheric cirrus over severe thunderstorms. J. Meteor. Soc. Japan, 60, 355-368.

Griffin, S. M., K. M. Bedka, and C. S. Velden, 2016: A method for calculating the height of overshooting convective cloud tops using satellite-based IR imager and CloudSat cloud profiling radar observations. J. Appl. Meteor. Climatol., 55, 479-491, https://doi.org/10.1175/JAMC-D-15-0170.1.

Hasler, A. F., K. Palaniappan, C. Kambhammetu, P. Black, E. Uhlhorn, and D. Chesters, 1998: High-resolution wind fields within the inner core and eye of a mature tropical cyclone from GOES 1-min images. Bull. Amer. Meteor. Soc., 79, 2483-2496, https://doi.org/ 10.1175/1520-0477(1998)079<2483:HRWFWT>2.0.CO;2.

Hayden, C. M., and R. J. Purser, 1995: Recursive filter objective analysis of meteorological fields: Applications to NESDIS operational processing. J. Appl. Meteor. Climatol., 34, 3-15, https://doi.org/10.1175/1520-0450-34.1.3.

Holmlund, K., 1998: The utilization of statistical properties of satellite-derived atmospheric motion vectors to derive quality 
indicators. Wea. Forecasting, 13, 1093-1104, https://doi.org/ 10.1175/1520-0434(1998)013<1093:TUOSPO > 2.0.CO;2.

Homeyer, C. R., and K. P. Bowman, 2017: Algorithm description document for version 3.1 of the three-dimensional gridded NEXRAD WSR-88D radar (GridRad) dataset. University of Oklahoma/Texas A\&M University, 23 pp., http:/gridrad.org/ pdf/GridRad-v3.1-Algorithm-Description.pdf.

_ J. D. McAuliffe, and K. M. Bedka, 2017: On the development of above-anvil cirrus plumes in extratropical convection. J. Atmos. Sci., 74, 1617-1633, https://doi.org/10.1175/JAS-D-16-0269.1.

Kalina, E. A., and Coauthors, 2017: The ice water paths of small and large ice species in Hurricanes Arthur (2014) and Irene (2011). J. Appl. Meteor. Climatol., 56, 1383-1404, https:// doi.org/10.1175/JAMC-D-16-0300.1.

Knupp, K. R., 1996: Structure and evolution of a long-lived, microburst-producing storm. Mon. Wea. Rev., 124, 2785-2806, https:// doi.org/10.1175/1520-0493(1996)124<2785:SAEOAL > 2.0.CO;2. , and Coauthors, 2014: Meteorological overview of the devastating 27 April 2011 tornado outbreak. Bull. Amer. Meteor. Soc., 95, 1041-1062, https://doi.org/10.1175/BAMS-D-11-00229.1.

Koshak, W. J., and Coauthors, 2004: North Alabama Lightning Mapping Array (LMA): VHF source retrieval algorithm and error analyses. J. Atmos. Oceanic Technol., 21, 543-558, https://doi.org/10.1175/1520-0426(2004)021<0543: NALMAL $>2.0 . C O ; 2$.

Krehbiel, P. R., R. J. Thomas, W. Rison, T. Hamlin, J. Harlin, and M. Davis, 2000: GPS-based mapping system reveals lightning inside storms. Eos, Trans. Amer. Geophys. Union, 81, 21-25, https://doi.org/10.1029/00EO00014.

— W. Rison, and R. Thomas, 2012: Lightning mapping observations during DC3 in northern Colorado. 2012 Fall Meeting, San Francisco, CA, Amer. Geophys. Union, Abstract AE12A-05.

Lakshmanan, V., T. Smith, G. Stumpf, and K. Hondl, 2007: The Warning Decision Support System-Integrated Information. Wea. Forecasting, 22, 596-612, https://doi.org/10.1175/WAF1009.1.

Lang, T. J., S. A. Rutledge, B. Dolan, P. Krehbiel, W. Rison, and D. T. Lindsey, 2014: Lightning in wildfire smoke plumes observed in Colorado during summer 2012. Mon. Wea. Rev., 142 489-507, https://doi.org/10.1175/MWR-D-13-00184.1.

Lemon, L. R., and C. A. Doswell, 1979: Severe thunderstorm evolution and mesocyclone structure as related to tornadogenesis. Mon. Wea. Rev., 107, 1184-1197, https://doi.org/ 10.1175/1520-0493(1979)107<1184:STEAMS>2.0.CO;2.

—, D. W. Burgess, and R. A. Brown, 1978: Tornadic storm airflow and morphology derived from single-Doppler radar measurements. Mon. Wea. Rev., 106, 48-60, https://doi.org/ 10.1175/1520-0493(1978)106<0048:TSAAMD>2.0.CO;2.

Line, W. E., T. J. Schmit, D. T. Lindsey, and S. J. Goodman, 2016: Use of geostationary super rapid scan satellite imagery by the Storm Prediction Center. Wea. Forecasting, 31, 483-494, https://doi.org/10.1175/WAF-D-15-0135.1.

McCann, D. W., 1983: The Enhanced-V: A satellite observable severe storm signature. Mon. Wea. Rev., 111, 887-894, https://doi.org/ 10.1175/1520-0493(1983)111<0887:TEVASO > 2.0.CO;2.

McCaul, E. W., Jr., J. C. Bailey, J. Hall, S. J. Goodman, R. J. Blakeslee, and D. E. Buechler, 2005: A flash clustering algorithm for North Alabama Lightning Mapping Array data. Conf. on Meteorological Applications of Lightning Data, San Diego, CA, Amer. Meteor. Soc., 5.3, https://ams.confex.com/ ams/Annual2005/techprogram/paper_84373.htm.

Mohr, C. G., L. J. Miller, R. L. Vaughan, and H. W. Frank, 1986: The merger of mesoscale datasets into a common Cartesian format for efficient and systematic analyses. J. Atmos. Oceanic
Technol., 3, 143-161, https://doi.org/10.1175/1520-0426(1986) $003<0143$ :TMOMDI $>2.0$. CO; 2 .

NCEI, 2018: Storm events database. National Centers for Environmental Information, accessed 10 August 2016, https:// www.ncdc.noaa.gov/stormevents/.

Nieman, S. J., J. Schmetz, and W. P. Menzel, 1993: A comparison of several techniques to assign heights to cloud tracers. J. Appl. Meteor., 32, 1559-1568, https://doi.org/10.1175/1520-0450(1993) 032<1559:ACOSTT>2.0.CO;2.

—, W. P. Menzel, C. M. Hayden, D. Gray, S. T. Wanzong, C. S. Velden, and J. Daniels, 1997: Fully automatic cloud drift winds in NESDIS operations. Bull. Amer. Meteor. Soc., 78, 1121-1133, https://doi.org/10.1175/1520-0477(1997)078<1121: FACDWI $>2.0 . \mathrm{CO} ; 2$

Orf, L., R. Wilhelmson, B. Lee, C. Finley, and A. Houston, 2017: Evolution of a long-track violent tornado within a simulated supercell. Bull. Amer. Meteor. Soc., 98, 45-68, https://doi.org/ 10.1175/BAMS-D-15-00073.1.

Oye, R., C. Mueller, and S. Smith, 1995: Software for radar translation, visualization, editing, and interpolation. Preprints, 27th Conf. on Radar Meteorology, Vail, CO, Amer. Meteor. Soc., 359-361.

Pruppacher, H. R., and J. D. Klett, 1997: Microphysics of Clouds and Precipitation. Kluwer Academic Publishers, $954 \mathrm{pp}$.

Purser, R. J., and R. McQuigg, 1982: A successive correction analysis scheme using recursive numerical filters. Met. O 11, Tech. Note 154, British Meteorological Service, 17 pp.

Ray, P. S., 1976: Vorticity and divergence fields within tornadic storms from dual-Doppler observations. J. Appl. Meteor., 15, 879-890, https://doi.org/10.1175/1520-0450(1976)015<0879: VADFWT $>2.0 . \mathrm{CO} ; 2$.

, K. K. Wagner, K. W. Johnson, J. J. Stephens, W. C. Bumgarner, and E. A. Mueller, 1978: Triple-Doppler observations of a convective storm. J. Appl. Meteor., 17, 1201-1212, https://doi.org/ 10.1175/1520-0450(1978)017<1201:TDOOAC>2.0.CO;2.

— C. L. Ziegler, W. Bumgarner, and R. J. Serafin, 1980: Singleand multiple-Doppler radar observations of tornadic storms. Mon. Wea. Rev., 108, 1607-1625, https://doi.org/10.1175/15200493(1980)108<1607:SAMDRO > 2.0.CO;2.

Rison, W., R. J. Thomas, P. R. Krehbiel, T. Hamlin, and J. Harlin, 1999: A GPS-based three-dimensional lightning mapping system: Initial observations in central New Mexico. Geophys. Res. Lett., 26, 3573-3576, https://doi.org/ 10.1029/1999GL010856.

Schmit, T. J., and Coauthors, 2013: Geostationary Operational Environmental Satellite (GOES)-14 super rapid scan operations to prepare for GOES-R. J. Appl. Remote Sens., 7, 073462 , https://doi.org/10.1117/1.JRS.7.073462.

Schultz, C. J., W. A. Petersen, and L. D. Carey, 2009: Preliminary development and evaluation of lightning jump algorithms for the real-time detection of severe weather. J. Appl. Meteor. Climatol., 48, 2543-2563, https://doi.org/10.1175/2009JAMC2237.1.

- - , and -2011 : Lightning and severe weather: A comparison between total and cloud-to-ground lightning trends. Wea. Forecasting, 26, 744-755, https://doi.org/10.1175/ WAF-D-10-05026.1.

, and Coauthors, 2012: Dual-polarization tornadic debris signatures. Part I: Examples and utility in an operational setting. Electron. J. Oper. Meteor., 13, 120-137.

, L. D. Carey, E. V. Schultz, and R. J. Blakeslee, 2015: Insight into the kinematic and microphysical processes that control lightning jumps. Wea. Forecasting, 30, 1591-1621, https://doi.org/ 10.1175/WAF-D-14-00147.1. 
,,--- , and $\longrightarrow, 2017$ : Kinematic and microphysical significance of lightning jumps versus nonjump increases in total flash rate. Wea. Forecasting, 32, 275-288, https://doi.org/ 10.1175/WAF-D-15-0175.1.

Setvák, M., and Coauthors, 2010: Satellite-observed cold-ringshaped features atop deep convective clouds. Atmos. Res., 97, 80-96, https://doi.org/10.1016/j.atmosres.2010.03.009.

Starzec, M., C. R. Homeyer, and G. L. Mullendore, 2017: Storm Labeling in Three Dimensions (SL3D): A volumetric radar echo and dual-polarization updraft classification algorithm. Mon. Wea. Rev., 145, 1127-1145, https://doi.org/10.1175/ MWR-D-16-0089.1.

Velden, C. S., C. M. Hayden, S. J. Nieman, W. P. Menzel, S. Wanzong, and J. S. Goerss, 1997: Upper-tropospheric winds derived from geostationary satellite water vapor observations. Bull. Amer. Meteor. Soc., 78, 173-195, https:// doi.org/10.1175/1520-0477(1997)078<0173:UTWDFG > 2.0.CO;2.

, T. L. Olander, and S. Wanzong, 1998: The impact of multispectral GOES-8 wind information on Atlantic tropical cyclone track forecasts in 1995. Part II: NOGAPS forecasts. Mon. Wea. Rev., 126, 1202-1218, https://doi.org/10.1175/ 1520-0493(1998)126<1202:TIOMGW > 2.0.CO;2.
— , and Coauthors, 2005: Recent innovations in deriving tropospheric winds from meteorological satellites. Bull. Amer. Meteor. Soc., 86, 205-223, https://doi.org/10.1175/BAMS-86-2-205.

Wang, P. K., 2003: Moisture plumes above thunderstorm anvils and their contributions to cross-tropopause transport of water vapor in midlatitudes. J. Geophys. Res., 108, 4194, https:// doi.org/10.1029/2002JD002581.

2007: The thermodynamic structure atop a penetrating convective thunderstorm. Atmos. Res., 83, 254-262, https:// doi.org/10.1016/j.atmosres.2005.08.010.

Witt, A., and S. P. Nelson, 1991: The use of single-Doppler radar for estimating maximum hailstone size. J. Appl. Meteor., 30 , 425-431, https://doi.org/10.1175/1520-0450(1991)030<0425: TUOSDR $>2.0 . \mathrm{CO} ; 2$.

Wu, Q., H.-Q. Wang, Y.-J. Lin, Y.-Z. Zhuang, and Y. Zhang, 2016: Deriving AMVs from geostationary satellite images using optical flow algorithm based on polynomial expansion. J. Atmos. Oceanic Technol., 33, 1727-1747, https://doi.org/ 10.1175/JTECH-D-16-0013.1.

Yost, C. R., and Coauthors, 2018: A prototype method for diagnosing high ice water content probability using satellite imager data. Atmos. Meas. Tech., 11, 1615-1637, https:// doi.org/10.5194/amt-11-1615-2018. 